\title{
LA ESCALERA DORADA DE LA CATEDRAL DE BURGOS *
}

\author{
POR \\ FABIO SPERANZA \\ Universidad Federico II de Nápoles
}

This essay analyses one of the most outstanding creations of the Spanish Renaissance. In particular the author dwells upon some Francesco di Giorgio Martini's drawings that should have inspired the architectural plan of the «Escalera Dorada», on the hypothesis of a relationship with Diego de Sagredo and his Medidas del Romano. The author concludes his work with a detailed exame of Siloesque ornamentation and its possible Italian models.

En Burgos, el 4 de Noviembre de 1519, el obispo Juan Rodríguez de Fonseca proponía al Capítulo de la Catedral reconstruir la escalera de la puerta alta, la cual él mismo había mandado derribar poco tiempo atrás ${ }^{1}$, siguiendo un nuevo proyecto presentado por Diego de Siloe: «Este día S.S.R.(el obispo), propuso sobre que quería tornar á facer la escalera en la puerta alta de la correria donde solia, la cual el había mandado quitar et que agora la quería facer conforme á una traza que mostró en el dicho Cabildo Diego Sylue imaginario, en presencia de S.S. é de los dichos señores» ${ }^{2}$. En los años de su permanencia en Burgos, entre el $1519 \mathrm{y}$ el 1527, Diego de Siloe se ocupa sobre todo de tareas escultóricas: la única obra arquitectónica conocida, obviando la Escalera Dorada (también llamada de la Puerta alta o de la Coronería ${ }^{3}$ ), es la torre del campanario de iglesia parroquial de Santa María del Campo en Burgos, para la

\footnotetext{
* El autor agradece a María Jesús Muñoz González la traducción de este artículo.

' La escalera anterior se mandó derribar por Fonseca en el 1516, contra la voluntad del Capítulo. La decisión del prelado quería poner remedio a una costumbre poco decorosa, ya que, a menudo, durante las celebraciones litúrgicas, los burgaleses, con todos sus enseres e incluso con su ganado, utilizaban la escalera como atajo de un punto a otro de la ciudad. Cfr. M. Martínez y Sanz, Historia del templo Catedral de Burgos, Burgos 1866 (ed. facsímil 1983), p. 125 y T. López Mata La catedral de Burgos, Burgos 1950, p. 284.

2 M. Martínez y Sanz, op. cit. p. 126. El documento se conserva en el Archivo de la Catedral de Burgos (desde ahora A.C.B.), Actas Capitulares de Fernando de Espinosa senor. Años 1516-1519. Registro 37, fol. 186v (no 168 como indica Martínez y Sanz).

3 Vicente Lampérez y Romea toma de nuevo el apelativo de escalera de los imperiales, menos común, que hace una evidente referencia a un tipo de escalera llamada «imperial», de estructura símil, pero más compleja, que hace su aparición después de la mitad del siglo xvı en El Escorial. Cfr. V. Lampérez y Romea, La Catedral de Burrgos, col. «El Arte en España», Barcelona s.d. (inicio siglo xx). El apelativo de Escalera Dorada, ya se le dio a finales del siglo xvı, y se debe al precioso efecto cromático, producto de la barandilla en hierro dorado.
} 

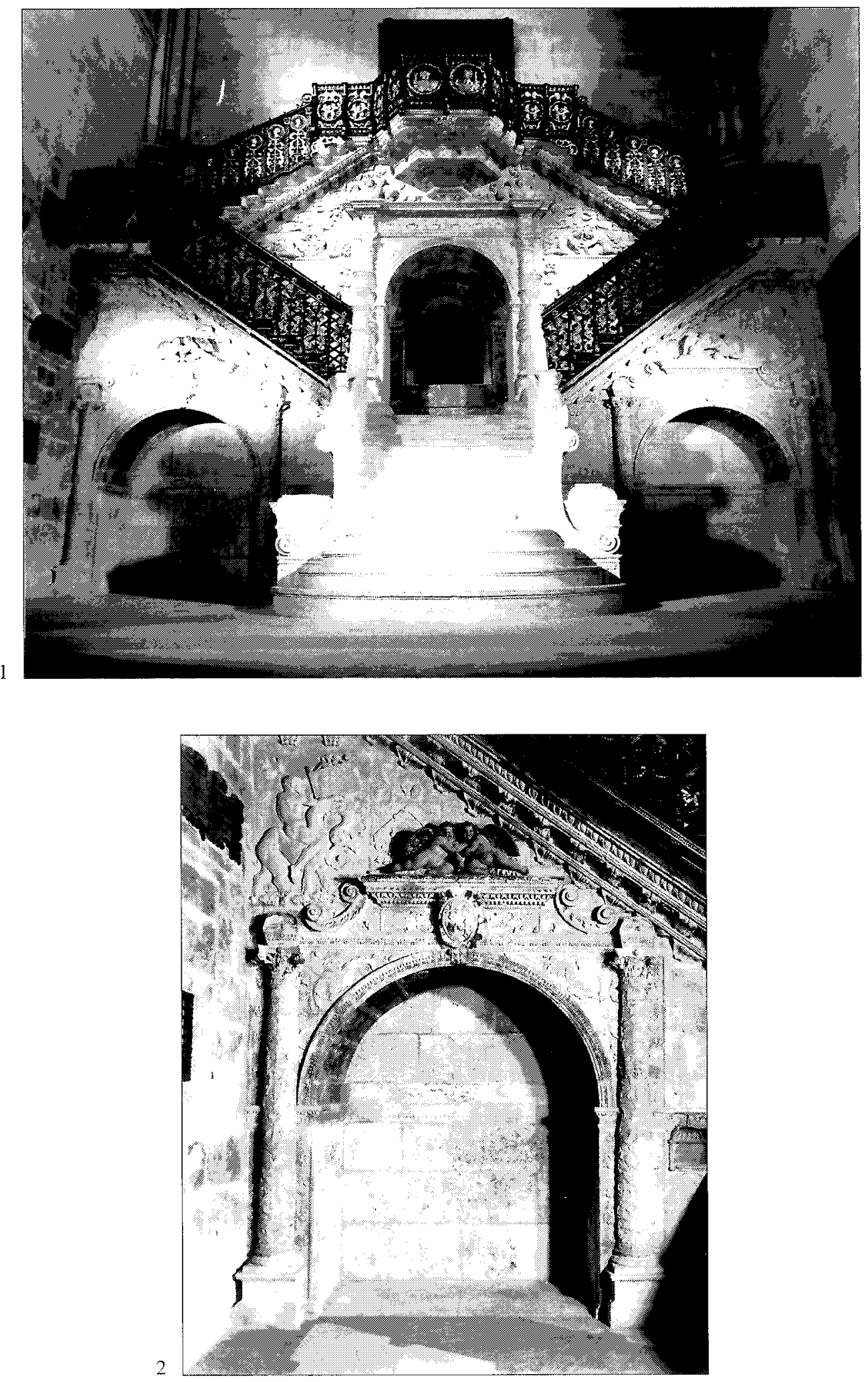

Fig. 1. Escalera Dorada, Burgos, Catedral.

Fig. 2. Escalera Dorada, Detalle del arco izquierdo, Burgos, Catedral. 
cual Diego solamente había realizado el proyecto, confiando su ejecución a Juan de Salas, pocos meses antes de marcharse a Granada ${ }^{4}$.

Terminada en el año $1522^{5}$, la Escalera Dorada se impone como verdadero manifiesto funcional de la arquitectura del renacimiento español, en un ambiente artístico todavía fuertemente unido a la tradición tardogótica (fig. 1), como atestigua la larga hegemonía ejercida por Juan, Simón y Francisco de Colonia, que, junto a la actividad de Gil de Siloe, padre de Diego, se resistirá incluso a los primeros tímidos intentos de acercamiento a las formas del renacimiento italiano llevadas a cabo por Felipe Bigarny en el trascoro de la catedral de Burgos.

Así pues, antes de que un decisivo giro hacia «lo italiano» cobre cuerpo gracias a la polítca de mecenazgo emprendida por Carlos $\mathrm{V}$ y su corte, un ejemplo paradigmático del compromiso, que al inicio del siglo xvı en Burgos se registra entre la tradición tardogótica y la difusión de modelos del renacimiento, está en la decoración plateresca de la Puerta de la Pellejería en la Catedral, realizada por Francisco de Colonia en 1516, por encargo del mismo obispo Fonseca, para sustituir a la Puerta de la Coronería cerrada después de la demolición de la vieja escalera del crucero. Aquí la secuencia de los ordenes arquitectónicos no responde al rigor y a la proporción del canon clásico, pues conforma una puerta cuya estructura responde todavía a la de los retablos góticos, en los cuales se engastan libremente motivos decorativos italianos, que derivan en su mayor parte de estampas ${ }^{6}$.

Muy diverso motivo, es el propuesto por Siloe, que desde su educación italiana que crece y madura a la sombra de Rafael, de Miguel Ángel y de los dos Sansovinos, demuestra un pleno dominio del lenguaje arquitectónico del renacimiento en la organización de los espacios, en la correspondencia de las formas y en la buscada simetría de las partes. Las condiciones en las cuales Diego comenzó a trabajar no eran las más oportunas. La escalera nació de la exigencia, al haberse demolido la antigua, de salvar el desnivel que existe entre el suelo de la iglesia y el ingreso de la puerta de la Coronería, situado en el testero norte del crucero, a más de siete metros y medio de altura, en correspondencia de la calle de la Rua Vieja, hoy calle Fernán González, que, en pendiente, recorre el costado de la catedral. Otra limitación añadida era la de que constituía la ya señalada Puerta de la Pellejería, que se abría en ángulo en la pared lateral del crucero, dejando a la nueva escalera unos escasos dos metros y medio de espacio disponible de profundidad. En estas condiciones tan restrictivas, Siloe concibió una construcción de perfecto equilibrio compositivo, desarrollada sobre un esquema de cinco rampas y dos brazos simétricos. La rampa inicial, central, único elemento que se proyecta de manera decidida hacia el espacio interno del crucero, presenta un arranque compuesto por cuatro escalones semicirculares. En correspondencia con el primer piso, sobre el cual se abre una amplia arcada enmarcada por columnas abalaustradas sobre la que se sitúan dos grifos, la escalera se bifurca, formando un ángulo de $90^{\circ}$ en dos rampas diagonales ascendentes, que después de alcanzar las paredes laterales del crucero, se repliegan, desde un segundo descansillo, en sentido opuesto, reencontrándose sobre un rellano al nivel de la Puerta de la Coronería. Destacan en gran medida tanto la rampa mediana, con las dos amplias volutas, las urnas a la antigua en las bases del parapeto, la pareja de grifos y los dos grandes jarrones; como la profunda arcada central en

${ }^{4}$ Sobre la Torre de Santa María del Campo. Cfr. L. Huidobro, Artistas burgaleses, Diego de Siloe, en «Boletín de la Comisión provincial de monumentos históricos y artísticos de Burgos», I (1922), n. 1, pp. 6-15; II (1923), n. 2, pp. 40-49, n. 3, 69-76; n. 4, 101-105; n. 5, 136-40; F. Chueca Goitia, Arquitectura del siglo xv, «Ars Hispaniae», XI, Madrid 1953, p. 79; P. Arroyo Gonzalo, Santa María del Campo (Burgos), Alcalá de Henares, 1954, pp. 39-54; M. A. Zalama, Diego de Siloe y la Torre de Santa María del Campo (Burgos), en «Boletín del Seminario de Estudios de Arte y Arqueología», LVI, 1990, pp. 404-12.

5 Una tasación de la reja de la Escalera en enero de 1523, hace pensar en que para dicha fecha estuviese ya terminada o al menos al finalizarse la obra en piedra. Para la documentación véase nota 9.

'J. M. Azcárate, Escultura del siglo Xvt, «Ar's Hispaniae», XIII, Madrid, 1958, p. 61. 


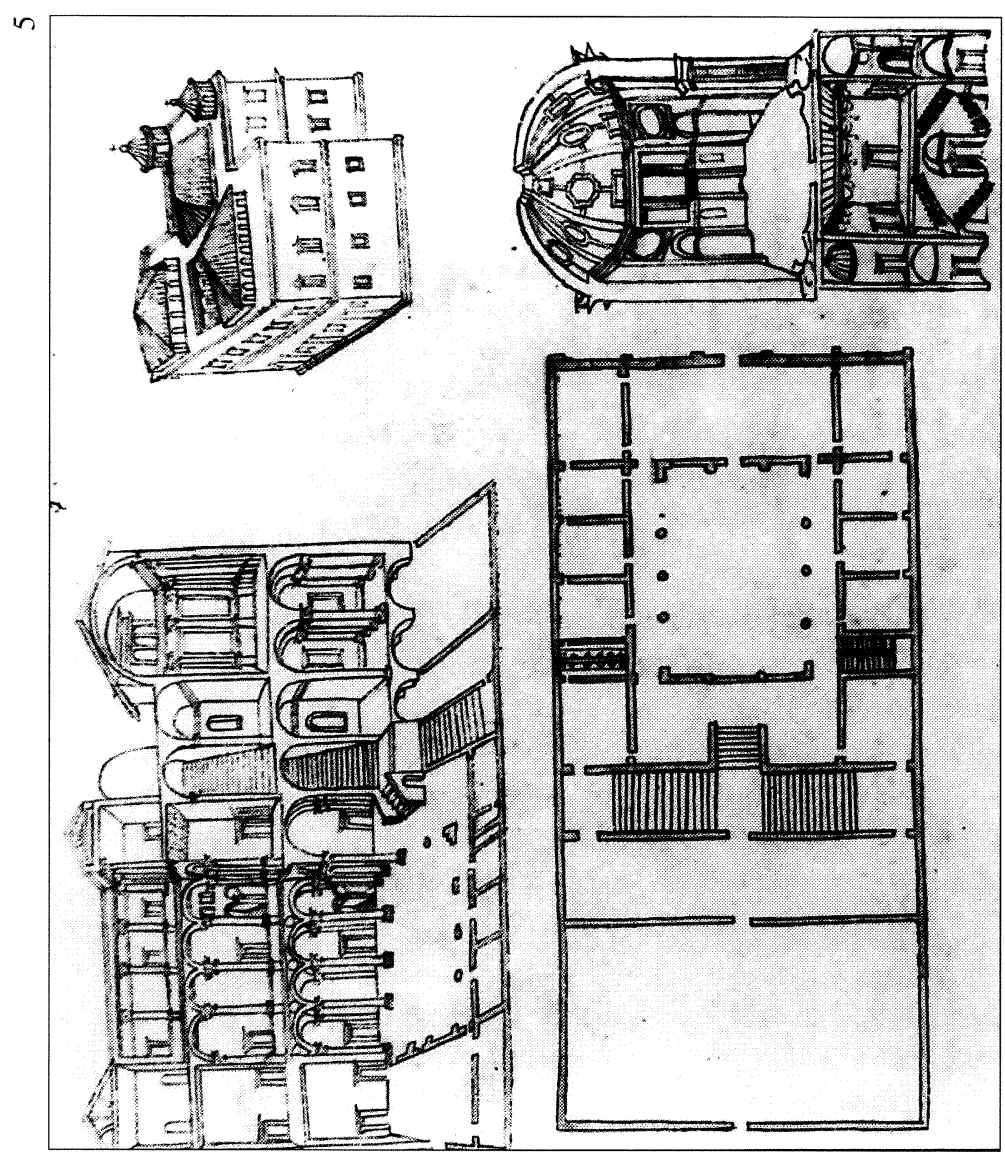

m

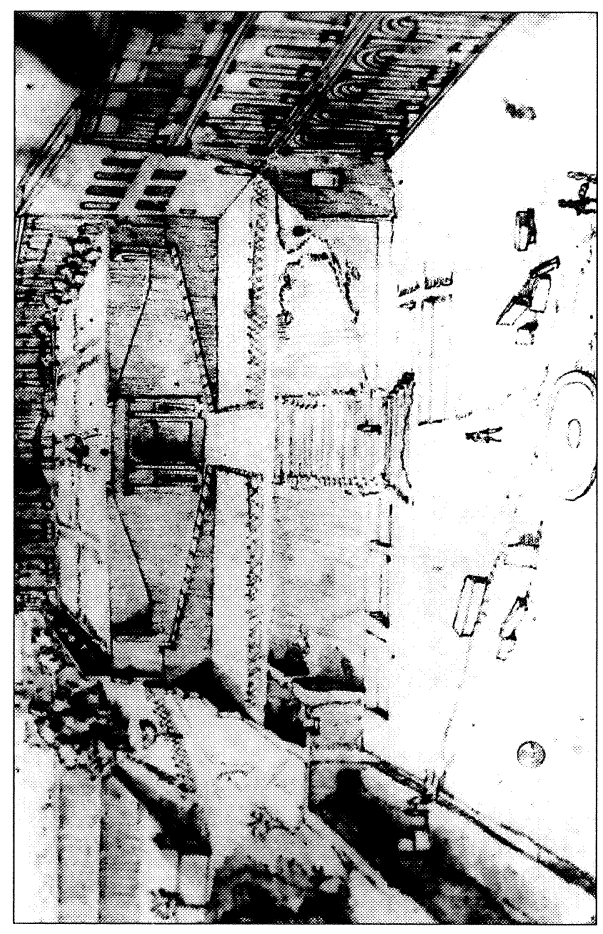

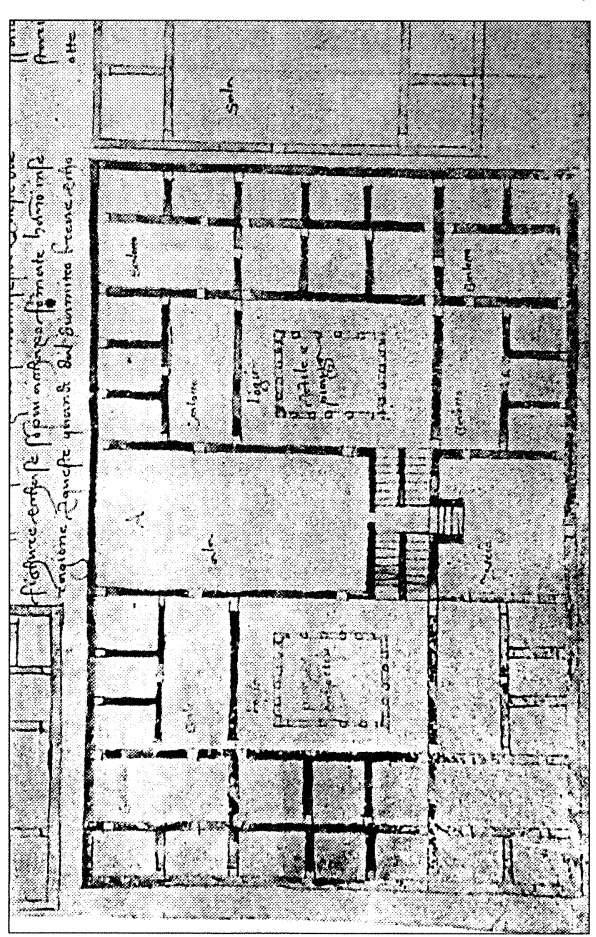

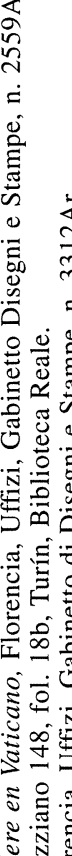

$\infty$ :

จ:

:

: $8:$

0

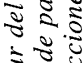

ज苟

จ

क्ष.

$8 \cdot \overline{1}$

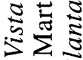

$0.0^{2}$

至

نี

نे

$\dot{m} \dot{x} \dot{0}$

on on on 
cuyo intradós están esculpidos once paneles con un fino repertorio di grutescos; como también resalta el balcón poligonal que asoma sobre lo alto de la obra.

En la parte baja, dispuestos simétricamente a los lados, se abren dos arcos, menos profundos que el mediano, con columnas corintias decoradas por un idéntico motivo de candelabros, un simple arco de medio punto rebajado y un curioso cornisamento de volutas rematado por una pareja de ángeles abrazados (fig. 2). En los extremos de la Escalera, están esculpidas, con gran relieve, dos figuras masculinas desnudas que, portando cada una una cartela, cabalgan animales de compuesta semblanza (figs. 9-10). Al lado de ambos aparece un refinado emblema de la práctica arquitectónica, una «firma» que Siloe sitúa bien a la vista casi para subrayar, el orgullo de quien, como él, había adquirido el conocimiento y el pleno dominio de las reglas de la composición arquitectónica: una escuadra, un compás y el nivel, que aparece colgado de un ovillo de hilos pegado a la pared por un grueso clavo ${ }^{7}$. Otras parejas de putti que muestran cartelas se disponen en el segundo nivel, acompañadas de carnosos y abundantes racimos de frutas (figs. 19, 21. Todavía en la decoración prevalecen los motivos zoo-antropomorfos, como los que se muestran a lo largo de las columnas abalaustradas de la arcada central, que resultan de una excelente calidad.

Un repertorio de criaturas fantásticas, palpitantes, auténtico signo distintivo de la decoración siloesca que, casi veinte años después, alcanzará una de sus cimas más relevantes en las esculturas de la Portada del Perdón de la Catedral de Granada.

La entera composición gira entorno a los elementos emergentes del panel central y, al mismo tiempo, atenúa su fuerte desarrollo vertical con la solución de la doble rampa de escalera tornante y con el gran relieve que se da a la barandilla de hierro dorado, realizada por el francés Hilario, sobre diseño de Diego, cuyo signo dinámico, contrasta con el empuje ascensional de la zona media. Ello, sin embargo, sin renunciar a una eficaz integración con las otras estructuras de la iglesia, en particular con el crucero, cuya planta poligonal encuentra correspondencia en el balcón que remata la construcción siloesca ${ }^{8}$.

La documentación relativa a la Escalera Dorada es muy escasa. Si para la balaustra tenemos noticias muy detalladas, que van de una primera tasación de una parte de la obra en Enero de 1523 , y otros pagamentos registrados después, entre el 1524 y el $1526^{9}$, para la obra en piedra tenemos solamente la breve noticia documental citada al inicio. Esta nota de archivo por

\footnotetext{
7 Emblemas similares caracteriza, aquí de modo exclusivo, la decoración d la tumba del escultor y arquitecto lombardo Andrea Bregno en Santa María sopra Minerva en Roma (1506). Volviendo a la escalera, la forma diferente de las dos cartelas, la de la izquierda de lados rectos y regulares, y la de la derecha por el contrario de silueta informe, ha hecho pensar a Fernando Marías en una posible alusión respectivamente a la buena y a la mala práctica arquitectónica. (F. Marías, El siglo xv, Gótico y Renacimiento, Madrid, 1992, p. 144).

${ }^{8}$ Cfr. A. L. Ampliato Briones, Muro, orden y espacio en la arquitectura del renacimiento andaluz. Teoría y práctica en la obra de diego Siloe, Andrés de Vandelvira y Hernán Ruiz II, Sevilla 1996, p. 65. La reciente restauración (1996-97) llevada a cabo en la Escalera ha conseguido eliminar los terribles daños causados a lo largo de los siglos por la enorme humedad, debida a la progresiva penetración del agua de la lluvia, que infiltrándose desde la calle elevada de Fernán González, iba a parar a la espalda del muro sobre el cual se apoya la escalera. El estado de conservación del monumento debía ser desde hace tiempo bastante precario puesto que, ya en el año 1804, Isidoro Bosarte señalaba como parte de la decoración, realizada en piedra arenisca, proveniente de la vecina cantera de Ontoria, se estaba consumiendo progresivamente por efectos de la humedad continua, de la cual él después acertó a entender el origen. Cfr. I. Bosarte, Viage artistico a varios pueblos de España, Madrid, 1804, pp. 310-12. Su malestar por el lamentable estado en que se encontraba la escalera, le hacía añadir: «Al tocar yo con los dedos algunos follages en que advertí más daño, se me deshacía la primera costra en una arena amarillenta. No hay más remedio[...] que hacer una mina, que reciba la humedad de las lluvias que baten contra la pared y puerta alta» (ibid., p. 312).

9 Un primer documento fechado en 5 de enero de 1523, hace relación a la tasación de una parte de la barandilla, ya comenzada la obra. Dos días después viene tasada una parte, todavía en el taller, establecido en un total de 2000 o 2100 ducados (A.C.B., Actas Capitulares de Fernando de Espinosa en que hay cosas tocantes al cabildo y particulares. Años 1519-1524, Registro 39, fol. 318, publicado parcialmente en M. Martínez y Sanz, op. cit., pp. 287-88). Tres años después, en abril del 1526, la obra se daba por terminada, aunque no se había colocado por entero. El 21 de Octubre del mismo año Hilario recibe el saldo definitivo por la reja de la Escalera (cfr. T. López Mata, op. cit., p. 286).
} 
otra parte, venía a confirmar una feliz intuición de Bosarte que había relacionado la decoración de la Escalera a los relieves presentes en la tumba del canónigo Diego de Santander en el vecino claustro (hoy obra indiscutible de Diego de Siloe), preguntándose si sería posible que ambas obras pudiesen atribuirse a la mano del gran burgalés, del cual lamentaba la absoluta falta de documentación de su actividad en la ciudad castellana. Le vino a sugerir esta atribución el recuerdo juvenil de las decoraciones vistas en la Catedral de Granada, cuya construcción, ya desde las fuentes impresas del siglo XvI, iba unida al nombre de Siloe ${ }^{10}$ : «Sus follages, las fisonomías de sus niños, sus uñas de leones, sus grifis, sus paños son tan originales, que no pueden confundirse fácilmente con otros», escribía admirado Bosarte ${ }^{11}$. Más adelante no dejaba de subrayar la cualidad de algunas figuras, como las parejas de putti abrazados sobre los arquitraves de las arcadas laterales o las dos figuras desnudas que montan bestias monstruosas ${ }^{12}$.

La primera lectura formal global de la Escalera Dorada corresponde a D. Manuel GómezMoreno, aunque ya se dieron por parte de Émile Bertaux algunas indicaciones sobre diversos detalles, en 1911, cuando escribió que la concepción arquitectónica de la Escalera «es completamente italiana y que la decoración revela una experiencia artística madurada necesariamente en Italia, quizá realizada en los mismos años de la estancia en la península de Alonso Berruguete» ${ }^{13}$. Gómez-Moreno, por su parte demostró haber comprendido perfectamente el carácter innovador de la escalera, obra maestra en su género en relación al ambiente artístico español, subrayando sobretodo la gran capacidad de inventiva derrochada por el burgalés en la abundante decoración dispuesta simétricamente de lado a lado. Un repertorio ornamental que Siloe y sus discípulos difundirían más tarde por Burgos y en Andalucía, en lo que quedaba de siglo. Llamaba la atención al investigador español, la inagotable fantasía desplegada en la «galería» de figuras fantásticas: criaturas antropomorfas, inquietantes grifos, feroces pájaros de larguísimos cuellos, serpientes marinas aladas y con patas de caballo, sátiros, un real y propio «Bestiario», a las que habría que añadir las imágenes más comunes de putti portadores de cartelas,

\footnotetext{
10 Lázaro de Velasco, en su traducción del tratado de Vitruvio, recuerda: «Diego Siloe natural de Burgos, escultor y arquitecto excellentissimo que prosiguió sobre lo que avia eregido el maestre Enrrique [[Egas] en la iglessia mayor de Granada y la muda al romano estando dispuesta al moderno» (publicado en F. J. Sánchez Cantón, Fuentes literarias para la historia del Arte Español, Madrid, 1923, I, p. 208). Sucesivamente Juan de Arfe (De varia commesuración para la esculptura y la architectura, Sevilla, 1585), escribirá de Diego como «maestro mayor de las fábricas de la cathedral y alcaçar de Granada», e incluso más tarde, fray José de Sigüenza, en su Historia de la Orden de S. Jerónimo, Granada 1600-1605, a propósito del homónimo monasterio granadino, menciona al burgalés como «el primero que con su buen juyzio pretendía resucitar la nobleza desde este Arte, aunque no pudo llegar a la fineza y buena imitacion de la antiguiedad. Era amigo de cargar de follages y figuras como se ve en esta fábrica, y la de la iglesia mayor...» (cfr. también por Juan de Arfe. F.J. Sánchez Cantón, op. cit., I, pp. 278-340).

"I. Bosarte, op. cit., p. 310.

12 En cualquiera de las viejas fotografías de los años treinta se puede ver el vano de la arcada izquierda de la Escalera, todavía ocupado por el altar del canónico don Bernardino Gutiérrez que, durante la segunda mitad del siglo xvı, había adquirido la parte del suelo que estaba delante del arco, para destinarlo a ser su tumba familiar (cfr. T. López Mata, op. cit., pp. 286-88). A cobijo del mismo arco se encontraba también una tela de fines del siglo xvi que representaba La última cena, copia de un cuadro de Juan de Juanes del Museo Provincial de Valladolid, relacionable iconográficamente con la Resurrección de Cristo del arco central, esta última dejada hasta ahora in situ y a su vez, derivada de una tela de Rubens conservada en la Catedral de Amberes. Hoy es posible todavía atisbar las señales de aquella construcción del siglo xvi. De hecho han permanecido en el lugar los escudos de la familia Gutiérrez, en la clave del arco y sobre el muro izquierdo con restos de policromía, y una inscripción, sin fecha, de Antonio Gutiérrez y de su mujer en la placa sobre el sarcófago siloesco de la izquierda. Considero probable que perteneciese al altar Gutiérrez incluso el pequeño nicho sobre el cual se sobrepone una cabeza de un ángel tallada en el intradós del arco. También debería achacarse a los restos de aquella obra, la policromía de la pareja de putti abrazados sobre el arquitrabe, que no ha sido eliminada en la reciente restauración, y las «huellas» rojizas todavía visibles en el intradós del arco.

13 «Cet escalier, élevé sur trois arcades triomphales et animé de silhouettes de chimères et d'amours, est si parfaitement italien par la disposition de ses rampes et la solennité de ses lignes qu’á date de 1523, qui est celle de son achèvement, il n'a pu, semblet-il, être dessiné que par un artiste qui avait fait le voyage d'Italie, vers le même temps que Berruguete» (É. Bertaux, La Renaissance en Espagne et en Portugal en A. Michel, Historie de l'Art, París 1911, IV, $2^{\circ}$, p. 966).
} 


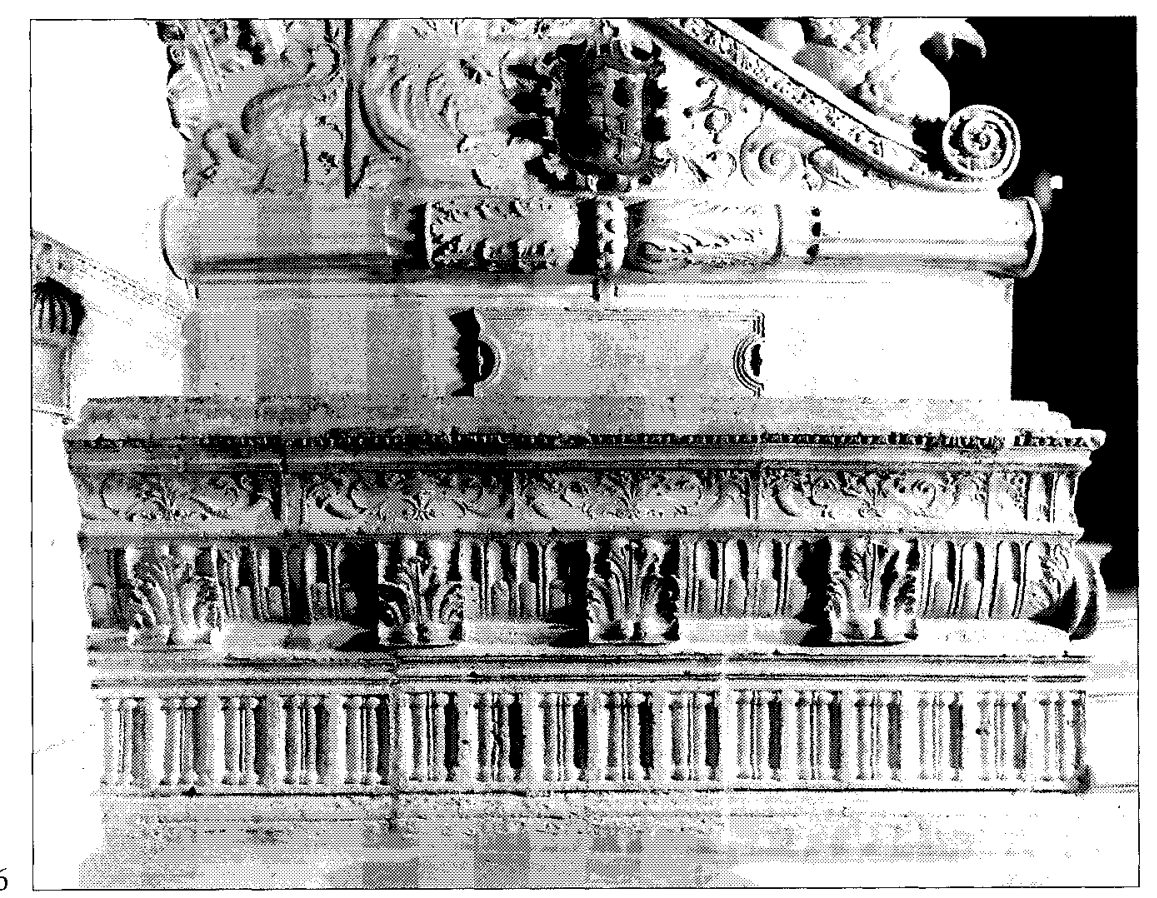

7

dida oterminada:como fon coluna q

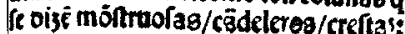
potras mucbas oiftrencias oeapars to: $Y$ en cada pna oellas entreviencel

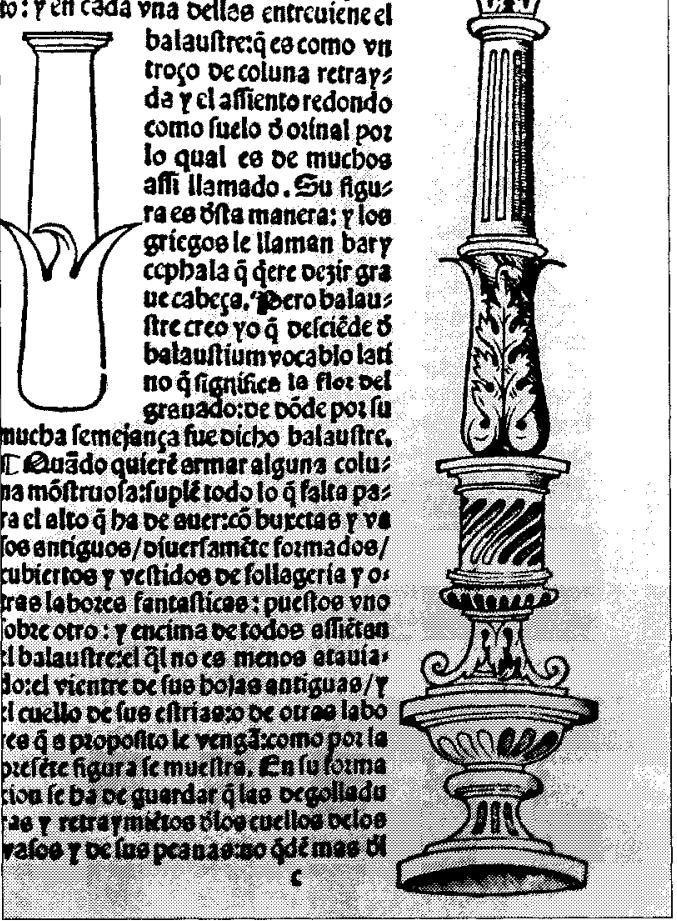

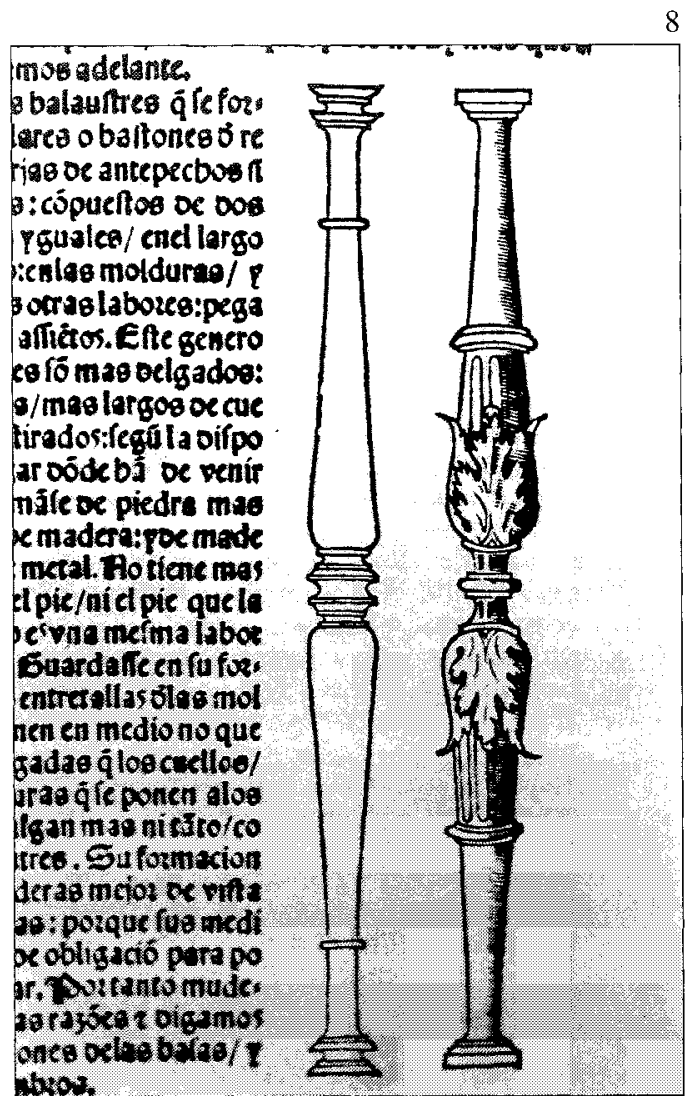

Fig. 6. Escalera Dorada, Sarcófago, Burgos, Catedral.

Fig. 7. D. de Sagredo, Medidas del Romano, Toledo 1526, fol. C.

Fig. 8. Ibidem, fol. CIIv. 
ángeles y candelabros. Sin detenerse a especificar, Gómez-Moreno incluso discernía entre los relieves distintos tipos de calidad, achacable a la presencia de diversas manos de ayudantes. A una idea del maestro correspondía también el antepecho del francés Hilario, así estrechamente ligado a la decoración en piedra ${ }^{14}$. Dos años posterior, es el ensayo sobre Ordóñez y sobre Siloe de Harold Wethey, que todavía hoy constituye un estudio fundamental en la reconstrucción de la carrera artística de ambos burgaleses ${ }^{15}$. Por lo que respecta a la Escalera Dorada, el atento análisis del historiador americano, superando los límites de una lectura exclusivamente formal, se centraba en la búsqueda de fuentes y de modelos. Así, el prototipo de esquema arquitectónico a $\mathrm{T}$ de la escalera burgalesa, con las dos rampas tornantes, y la amplia abertura central, sería para Wethey un reflejo de la proyectada por Bramante para el patio del Belvedere en el Vaticano, destruida después, como es sabido, bajo el pontificado de Pío V para dejar sitio a la Librería Vaticana. Un diseño de Giovan Antonio Dosio, del 1560 circa, conservado en los Uffizi, da testimonio del estado y de los trabajos por aquellas fechas y, perdida la obra original, nos aporta una idea de la construcción bramantesca que, dejada inacabada por la muerte del arquitecto, fue seguidamente modificada por Antonio de Sangallo el Joven (fig. 3) ${ }^{16}$. Siguiendo las noticias de Vasari, del proyecto de Bramante habría existido incluso un modelo, muy alabado y admirado, que Diego por tanto habría podido ver en Roma ${ }^{17}$. Es por otra parte sabido, que Bramante se inspiró en el Templo de la Fortuna Viril en Palestrina, muy conocido en la época, y no se debería excluir la idea de que Siloe, entre Roma y Nápoles, pudiese haber visto con sus propios ojos el mismo antiguo modelo, recogido por Bramante, llevando a elaborar el esquema de la Escalera de manera autónoma ${ }^{18}$. Pero pienso como Wethey hizo, ya que sostuvo más verosímil una filiación bramantesca, incluso porque la solución propuesta por el cortile vaticano catalizó, con su carga de novedad, la atención de los arquitectos del tiempo, que vieron dar forma a la primera grande escalera externa del renacimiento ${ }^{19}$.

Todavía el esquema adoptado por Diego de Siloe encuentra singulares afinidades incluso con algunos diseños de Francesco di Giorgio Martini, fuente imprescindible para arquitectos como Giuliano y Antonio da Sangallo y por el mismo Rafael, que llegaron a experimentar en sus estudios sobre la antigüedad elaboraciones análogas a aquella propuesta por Bramante para el Cortile del Belvedere. Nikolaus Pevsner afirmó que fue el mismo Francesco di Giorgio, anticipándose a los demás y paralelamente a las ideas leonardescas sobre la escalera espiraliforme, quien aportó en sus tratados proyectos, rápida y ampliamente desarrollados, de escaleras de un carácter absolutamente original que encontraron una realización efectiva antes que en

\footnotetext{
14 M. Gómez-Moreno, Las águilas del Renacimiento español, Madrid 1941 (ed. cons. Madrid 1983), pp. 45-46.

15 H. E. Wethey, The Early Works of Bartolomé Ordónez and Diego de Siloe, en «The Art Bulletin», XXV, 1943, pp. 226-38; 325-51. H. E. Wethey, The Early Works of Bartolomé Ordónez and Diego de Siloe, en «The Art BuIletin», XXV, 1943 , pp. 226-38; 325-51.

${ }^{16}$ Una versión más fiel del proyecto original de Bramante, sería según Santiago Sebastián, un fresco di Perin del Vaga en el apartamento del Castellano en Castel Sant'Angelo, fechable entre 1537 y el 1541 (S. Sebastián López, La Escalera Dorada de la Catedral de Burgos, en «Goya. Revista de Arte», 47, 1962, p. 356). El diseño de Dosio corresponde al número de inventario 2559A del Gabinetto Disegni e Stampe de los Uffizi.

17 G. Vasari, Le Vite de' piu eccellenti pittori, scultori ed architettori, Firenze 1568 (ed. crítica a cargo de G. Milanesi, Florencia 1906), IV, p. 158.

18 Ackerman, en su monografía sobre el Cortile del Belvedere, hipotizaba que incluso los Ilamados «Orti Aciliani», restos de una villa antigua sobre la colina del Pincio en Roma, podían haber inspirado el proyecto bramantesco, antes de que allí fuese edificada Villa Medici. Un diseño de Pirro Ligorio, en parte quizá fruto de una reconstrucción, muestra la villa a mitad de siglo, caracterizada por la grande escalera a doble rampa y arranque central y por la exedra al fondo para hacer de bastidor escenográfico como en el cortile vaticano. (J. S. Ackerman, The Cortile del Belvedere, Roma 1954, pp. $50-51)$.

19 Edificios de carácter escenográfico con escaleras al exterior serán a partir de entonces una característica de la arquitectura del siglo Xvi, baste pensar en la Villa Farnese di Caprarola de Vignola o en la Villa d'Este de Pirro Ligorio en Tivoli.
} 

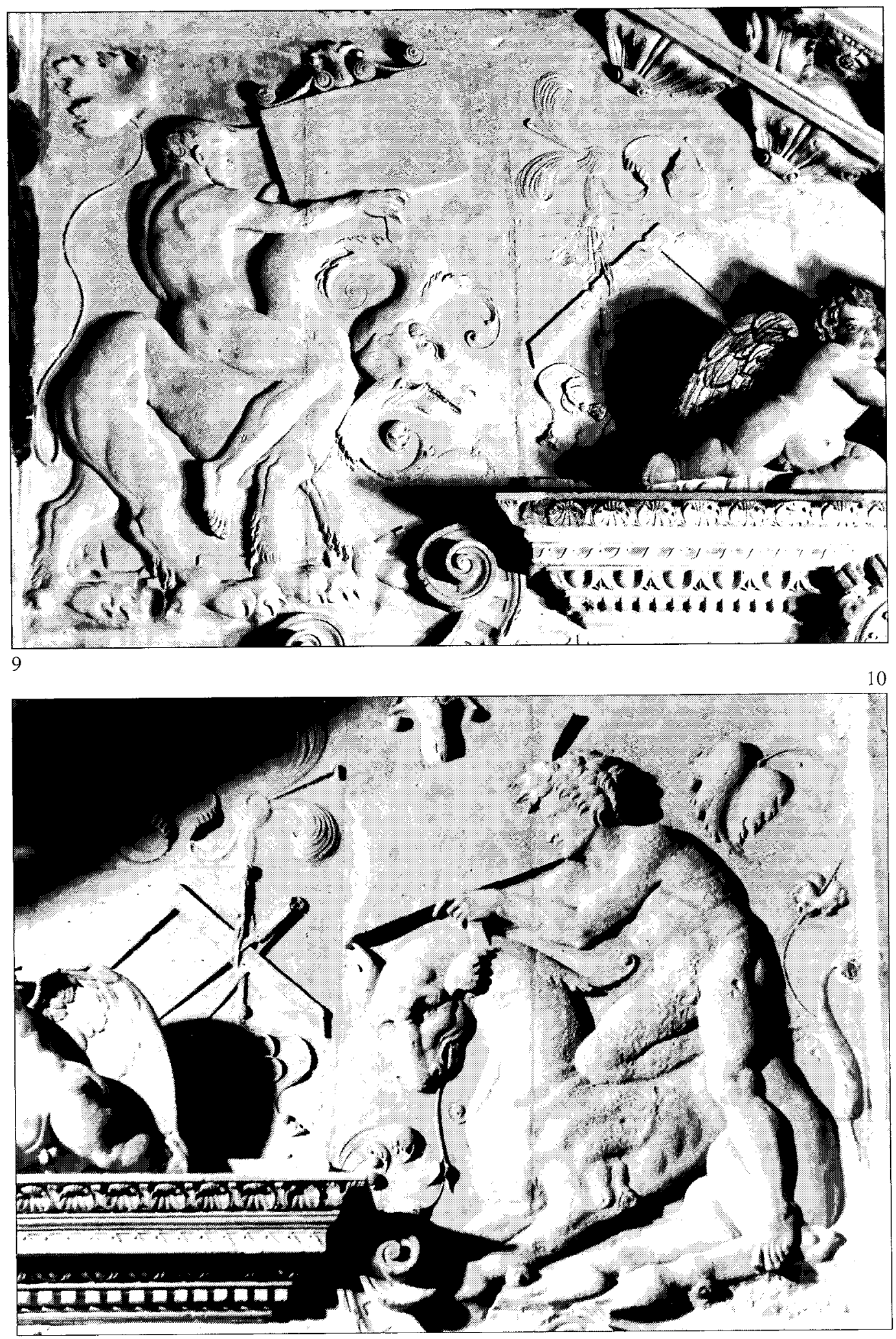

Fig. 9. Escalera Dorada, Figura de joven desnudo (lado izquierdo), Burgos, Catedral Fig. 10. Escalera Dorada, Figura de joven desnudo (lado derecho), Burgos, Catedral. 
Italia propiamente en España ${ }^{20}$. Una de estas soluciones, que Pevsner indicaba como posible fuente para el mismo Bramante, está dibujada en un bosquejo para un «Palacio de República» donde encontramos una escalera en forma de $\mathrm{T}$ que de un patio porticado conduce a un vestíbulo superior, a través de una rampa central que se bifurca después en dos ramas laterales ${ }^{21}$. Sin embargo, aquí está ausente el replegamiento de la escalera a $180^{\circ}$ que caracteriza la idea de Vasari, recogida después por Siloe. A mi me parece, por el contrario, que un modelo más próximo al esquema de la Escalera Dorada se ha de buscar en otro diseño de Francesco di Giorgio, contenido en el Codice Saluzziano di Torino, como fue ya sugerido por Fernando Marías (fig. 4). En el proyecto de esta escalera, incluida en un edificio de dimensiones no muy grandes, se encuentra la idea del breve arranque central del cual se desarrollan dos rampas que vuelven, que superado el piso de una galería se reencuentran en el nivel superior de una gran sala. «Se casa comoda e di non molta estensione, piglia lo spazio di piei cento quaranta e longo dugento dieci, laddove in prima [faja] quadrato atrio largo e longo piei quaranta, e in mezzo d'esso fagli una scala di sei scaloni, ed abbi due rivolte [rampas convergentes] da man destra e sinistra con due quadrati cortili, e che ciascuno abbi l'entrata in una sala che infra l'uno e l'altro cortile serà, di longhezza piei ottanta e in larghezza piei quaranta» ${ }^{22}$. Las condiciones ambientales hipotizadas por el sienés son por otra parte más semejantes a aquellas en las cuales debió trabajar Diego de Siloe. De hecho la escalera ideada por Bramante se incluye en un contexto de carácter «urbano», es una estructura externa, abierta y con un fuerte desarrollo horizontal, precedente directo de los proyectos de Rafael y de su taller para los jardines de Villa Madama; Siloe, que quizá por tiempo pudo conocer estos proyectos, es capaz, aún, de reinventar, probablemente a partir de modelos de Francesco di Giorgio Martini, la solución bramantesca infiriéndola en un ambiente pequeño, cerrado y de destacable desnivel en altura, ideando una construción vuelta sobre si misma e diferenciándola del prototipo romano sobretodo por el papel destacado que ocupan los elementos ornamentales.

Me parece útil insistir en la importancia de los estudios de Francesco di Giorgio en la escala de rampas que vuelven, como precedente común a Bramante y a Diego de Siloe. Una fiel traducción de una idea del arquitecto sienes está, de hecho, contenida en un cuaderno de dibujos de arquitectura de Pietro Cataneo, preparatorio para la publicación del tratado del mismo Cataneo ${ }^{23}$. Se ha podido demostrar, que este cuaderno, conservado en el Gabinetto di Disegni e Stampe de los Uffizi, constituye por lo menos una réplica puntual, entorno a los años $30 \mathrm{del}$ siglo Xvi, de las teorías de Martini ${ }^{24}$. En el folio 3312 Ar se ve, a la izquierda, un palacio representado en planta y en un corte en perspectiva, que representa una variante de la planta en

\footnotetext{
${ }^{20}$ Según Pevsner una idea de Francesco di Giorgio relativa a una trompa de escaleras abiertas con tres rampas que se suceden en la subida articulándose a lo largo de los lados de un espacio cuadrangular (cfr. por ejemplo el codice Magliabechiano II.I.141, fol. 20 de la Biblioteca Nacional de Florencia), si encuentra muy tempranamente en Toledo en la iglesia de San Juan de los Reyes de Enrique Egas (finalizada en 1504), así como en el Hospital de Santa Cruz y Castillo de la Calahorra. Cfr. N. Pevsner, An outline of European Architecture, Londres 1960 (ed. it. cons. Storia dell'architettura europea, Milán 1966, pp. 472-73). Véase también el importante ensayo de H. E. Wethey, Escaleras del primer Renacimiento español, en «Archivo Español de Arte», XXXVII, 1964, pp. 295-305.

${ }^{21}$ N. Pevsner, op. cit., pp. 473-78. El diseño, parte de una serie de estudios sobre plantas de palacios públicos, está contenido en el Codice Magliabechiano II.I.141 a fol. 23v.

${ }^{22}$ Trattato di architettura civile e militare (codice T), Torino, Biblioteca Reale, codice Saluzziano 148, fol. 18v, publicado en F. di Giorgio Martini, Trattati di architettura, ingegneria e arte militare (a cargo de C. Maltese), Milano 1967, I, p. 75, lám. 32. Cfr. también la introducción crítica de F. Marías, Bramante en España contenida en la edición española del libro de A. Bruschi, Bramante, Madrid 1987, p. 16.

23 P. Cataneo, L'Architettura, Venecia, 1567.

${ }^{24}$ Gabinetto Disegni e Stampe de los Uffizi, fols. 3275-3312A. Para toda la cuestión critica: cfr. M. Morresi, La fortuna di Francesco di Giorgio architetto. Dalle invenzioni dei Trattati a palazzo Thiene a Vicenza, in Francesco di Giorgio architetto, a cargo de F.P. Fiore y M. Tafuri, cat. de la exposición de Siena, 25 Abril-31 Julio 1993, Milán 1993, pp. 390-98 (con bibliografía precedente)
} 


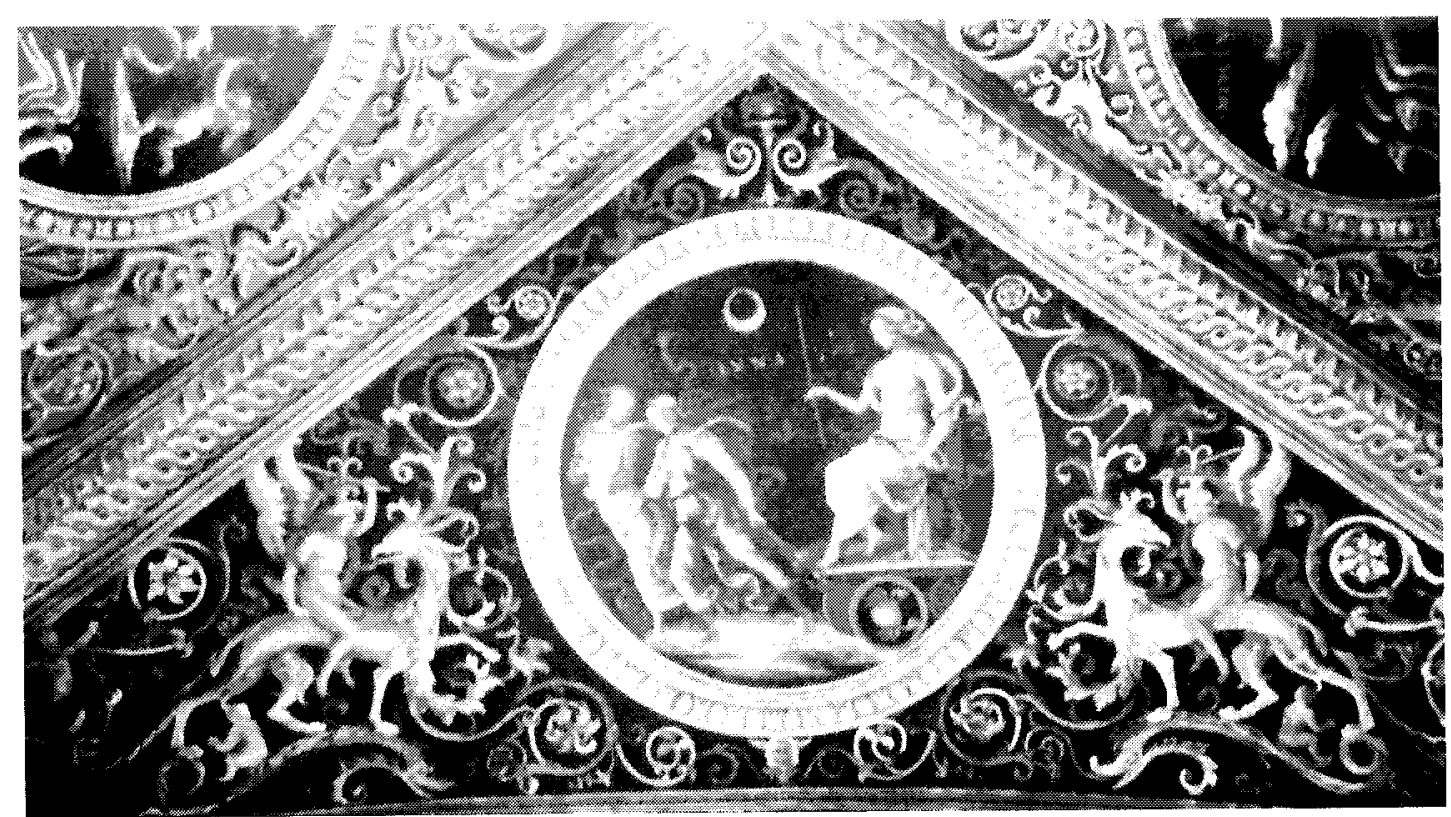

11
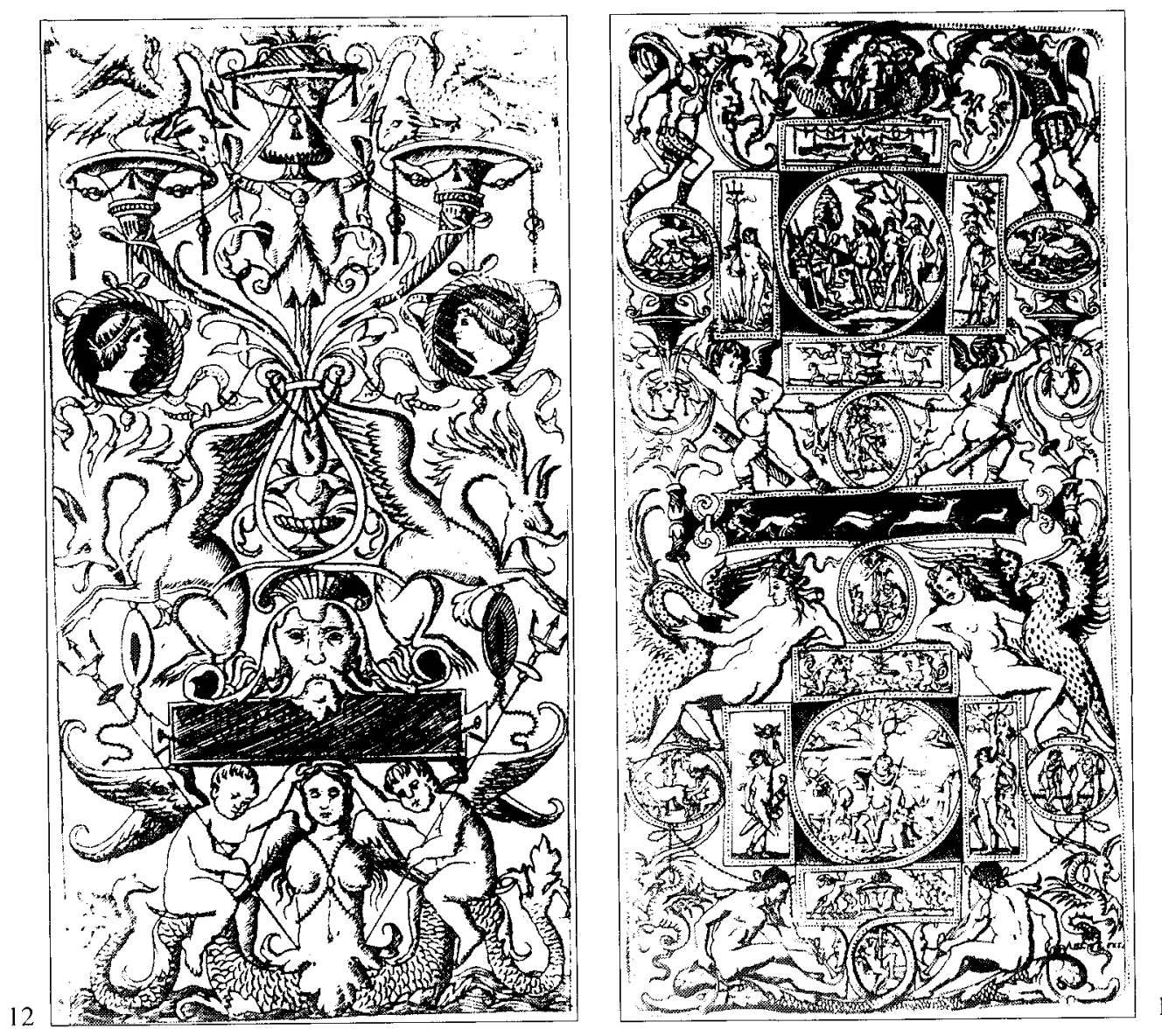

Fig. 11. P. Perugino, La Luna, Bóveda de la Sala dell'Udienza, Perugia, Collegio del Cambio.

Fig. 12. Nicoletto da Modena, Grabado con la inscripción «Un bel morir tuta la vita honora".

Fig. 13. Nicoletto da Modena, El juicio de Paris y Orfeo que amansa las fieras. 
bajo a la izquierda del Magliabechiano en el fol. $18 \mathrm{v}$, con una escalera similar a aquella del diseño citado en primer lugar del Codice Saluzziano, en el cual falta el replegamiento en ángulo llano de las dos rampas. Al margen derecho del mismo folio están, por el contrario dos borrones que se nos llevan con extrema precisión a diseños de Francesco di Giorgio (fíg. 5). El edificio en la parte de arriba, que aquí no interesa, está igualmente tomado de la planta en la parte baja a la izquierda del fol. 20v del Magliabechiano, mientras el corte que esta debajo no es otra cosa que un estudio para la «sala y atrio», cuadrada con ábsides angulares que aparece en planta en le folio 20r y v. siempre del Codice Magliabechiano ${ }^{25}$. Es interesante subrayar, en la idea de las dos tramos laterales convergentes que encuadran una apertura central, la correspondencia con el esquema propuesto por Siloe en Burgos.

Todo esto no quiere disminuye la importancia del modelo bramantesco del Belvedere, pero no es excluible que Siloe, quizá en el mismo Nápoles, llegase a tener conocimiento de las soluciones teóricas de Francesco di Giorgio Martini, más en relación con la problemática a la cual se enfrentaría en Burgos ${ }^{26}$. Por otra parte, aproximadamente un decenio más tarde, los modelos del sienés, debían permanecer todavía frescos en su memoria ya que, como sugería Rosenthal, la idea del transepto transformado en una rotonda con deambulatorio adaptada en la nueva planta «romana» de la Catedral de Granada, debe algo incluso a algunos proyectos de Francesco di Giorgio ${ }^{27}$.

Antes de pasar al examen de la rica decoración de la Escalera Dorada, quisiera detenerme brevemente en un aspecto que aquí merece alguna reflexión: me refiero a la hipótesis de una relación (directa o indirecta, por ahora no es posible establecerlo) entre Diego de Siloe y Diego de Sagredo, su paisano. Los años de ejecución de la Escalera coinciden con aquellos de la redacción de las Medidas del Romano, completada con toda probabilidad en Burgos en $1524{ }^{28}$. Como es sabido la obra de Sagredo se puede definir como un tratado pre-arquitectónico, es decir una introducción al lenguaje de la arquitectura clásica referente solo a sus aspectos formales y decorativos, sin entrar en el mérito de las leyes y de la sintaxis que lo gobiernan. Sagredo muestra tener una idea bastante limitada de la arquitectura antigua porque su interés se concentra exclusivamente en la composición morfológica de los órdenes clásicos y sobre las diversas combinaciones de varios elementos ${ }^{29}$.

El planteamiento dado por el tratadista a su escrito refleja eficazmente el concepto de «clásico» que en la península ibérica se da al menos en los 20 primeros años del siglo XVI en el llamado estilo plateresco: una decoración genéricamente «a la romana» libremente aplicada

${ }^{25}$ El diseño 3312Ar está reproducido en M. Morresi, op. cit., p. 397. Para el folio 20 del Codice Magliabechiano cfr. F. di Giorgio Martini, op. cit., II, láms. 199-200.

${ }^{26}$ El humanista napolitano Pietro Summonte, en su conocida Lettera a Marcantonio Michiel del 20 de Marzo de 1524 , recuerda a Francesco de Siena entre los arquitectos «más estimados» que se encontraban en Nápoles en la corte aragonesa para trabajar en la Villa de Poggioreale (F. Nicolini, L'arte napoletana del Rinascimento e la lettera di P. Summonte a M.A. Michiel, Nápoles 1925, p. 172).

27 Las referencias más recurrentes, aunque ninguna verdaderamente decisiva, son aquellas a la Catedral de Pavia, y sobre todo a la rotonda de la Annunziata en Florencia. Para Francesco di Giorgio, el historiador hacía referencia en particular a un estudio de iglesia con planta de cruz latina, contenido en el Codice Laurenziano-Ashburniano 361, fol. 11r. E. E. Rosenthal, The Cathedral of Granada. A study in the Spanish Renaissance, Princeton 1961 (trad. española cons: La Catedral de Granada. Un estudio sobre el Renacimiento español, Granada 1990, p. 73, fig. 64).

${ }_{28}$ La Real Cédula de Carlos V, por la cual se concedía a la obra de Sagredo una licencia para quince años de impresión, se da en Burgos el 15 de Julio de 1524 (cfr. la edición crítica a cargo de F. Marías e A. Bustamante del tratado de D. de Sagredo, Medidas del Romano, Madrid 1986, p. 17).

2.) Es explicativo el subtítulo de la primera edición de Toledo del 1526: Medidas del Romano: necessarias a los oficiales que quieren seguir las formaciones de las Basas/Colunas/Capiteles/y otras pieças de los edificios antiguos. Las fuentes principales a las cuales Sagredo parece recurrir son Vitruvio, naturalmente y Leon Battista Alberti. Es verosímil que para respecto al primer tratadista, el burgalés utilizase las dos ediciones de fra Giocondo (Venecia, 1511 y Florencia, 1513) y de Cesare Cesariano (Como, 1521), mientras que para el De re aedificaroria se sirvió probablemente de la edición francesa del 1512. Cfr. D. de Sagredo, op. cit., p. 63. 

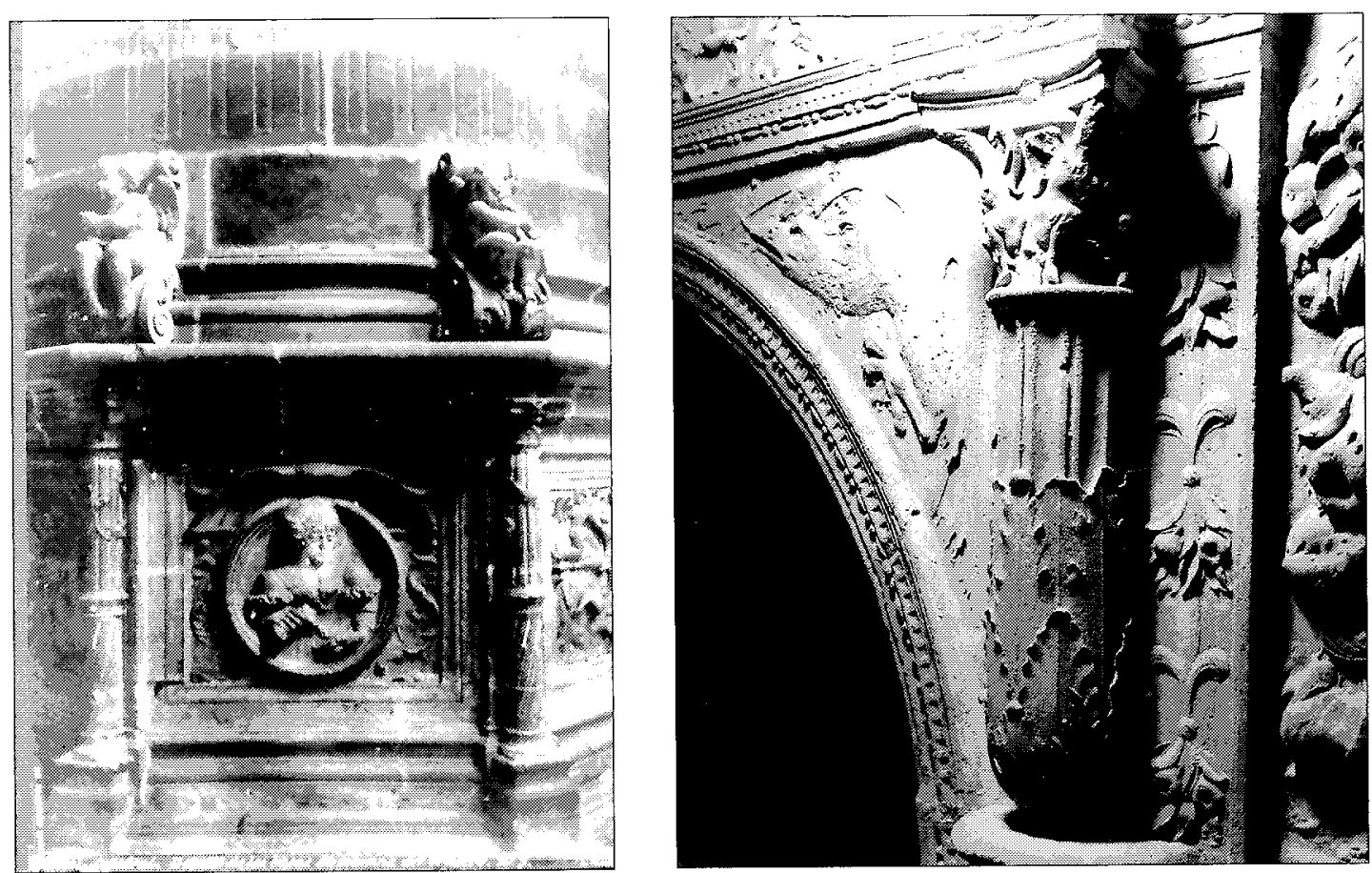

14

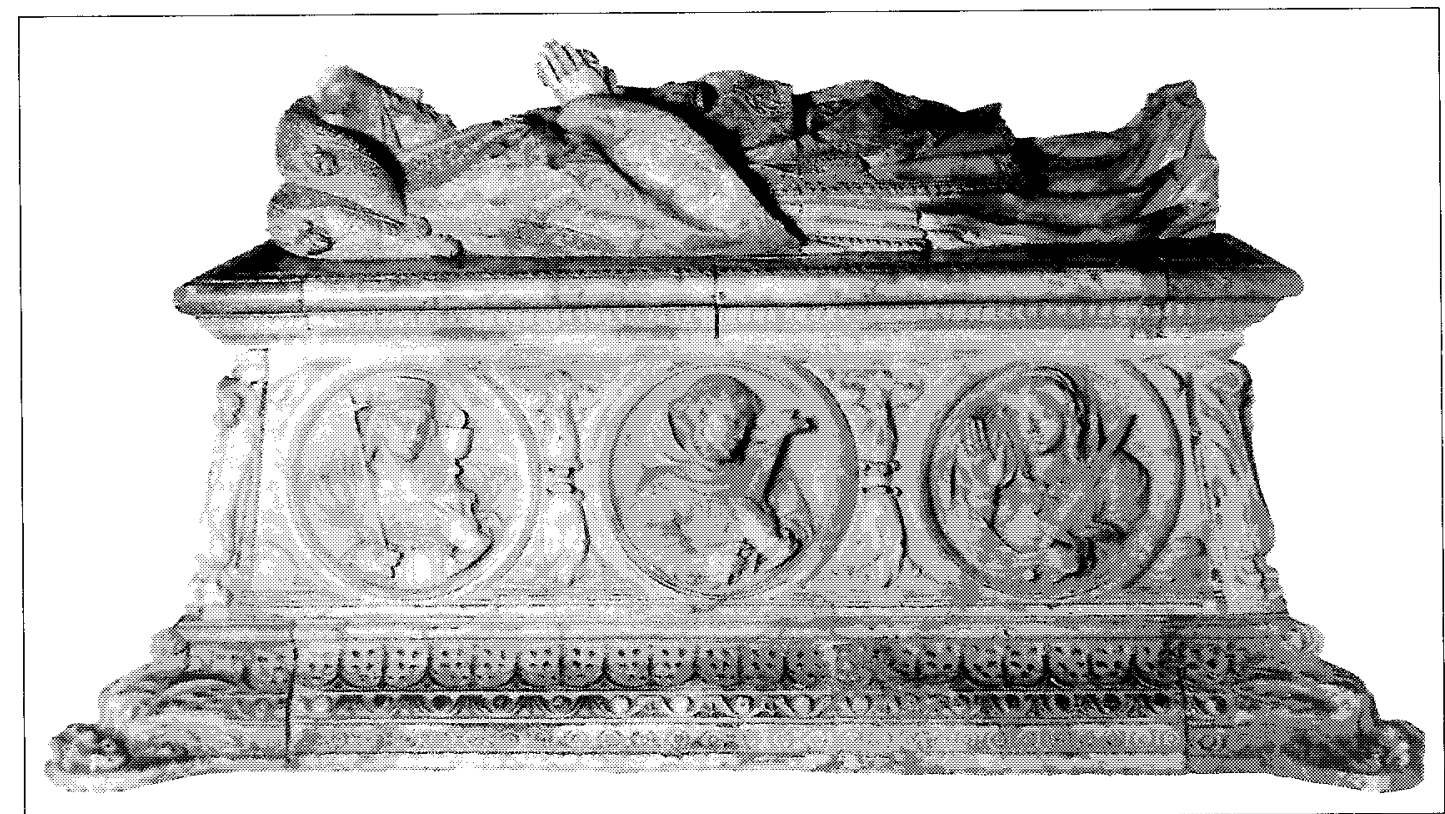

Fig. 14. F. Bigarny y taller, La Temperancia, pilastra del crucero, Burgos, Catedral.

Fig. 15. Escalera Dorada, Detalle de una columna abalaustrada del arco central, Burgos, Catedral.

Fig. 16. F. Bigarny, Tumba de don Gonzalo de Lerma, Burgos, Catedral. 
más allá de las leyes clásicas sobre estructuras todavía tardogóticas. Significativo es el hecho de que Sagredo acepte de buen grado la decoración de todos los elementos arquitectónicos con «follages, conchas fenestras, escamas, espichios, vergas» convencido de que, en una en una concepción de naturalismo mal entendido, «no ay arte donde así se puedan emplear las obras de natura y fantasías del hombre como la romana» ${ }^{30}$. Así pues, a primera vista considerando solamente el aspecto de la construcción arquitectónica, las posiciones de Siloe y Sagredo resultan sin duda diametralmente opuestas, «moderna» y por tanto vitruviana la del primero, y conservadora la del segundo. Un argumento que sería suficiente para justificar el absoluto silencio sobre Siloe en las Medidas. La exclusión de Siloe resulta aún más sorprendente porque Sagredo, documentado como se ha dicho en Burgos en 1524, tuvo todo el tiempo para ver terminada la Escalera con todo su aporte de novedades, antes de entregar en imprenta su manuscrito de las Medidas del Romano.

$\mathrm{Si}$, entonces, este silencio puede ser interpretado como el signo del rechazo hacia una estética considerada demasiado revolucionaria, la posición de Siloe se muestra por el contrario mucho más flexible y abierta en su comparación con la tradición, al menos en el aspecto de la decoración. Quiero señalar por tanto que la Escalera representa, también en sus contenidos innovadores, una especie de compromiso entre la pura decoración del renacimiento italiano y el estilo plateresco. Ya en su tiempo Santiago Sebastián hizo una distinción fundamental en la Escalera burgalesa «que por su composición pertenece ya al Pleno Renacimiento, pero está todavía recargada del grutesco dominante en el Protorrenacimiento» ${ }^{31}$. En la Escalera de hecho la decoración sobrepaso los límites impuestos por las estructuras arquitectónicas para producir un efecto global que, también en el hecho de la correspondencia simétrica, se aleja en parte de la norma y del rigor del ornato clásico. Si el repertorio decorativo, considerado separadamente en cada elemento individualizado, nos lleva a modelos tomados de fuentes directas o a través de estampas y cuadernos de dibujos a la antigua, el modo en el cual este repertorio se utiliza y compone parece seguir un gusto y una imaginación de sabor todavía nórdico, incluso por la clara prevalencia del elemento zoomorfo y del fantástico. En este sentido, las palabras ahora recordadas por Sagredo sobre la acepción de decoración «a la romana» resultan paradigmáticas.

Todavía más decisivo se muestra, a mi parecer, el examen de algunas soluciones técnicas adoptadas por Siloe: las columnas de los arcos laterales, rematadas por encima de los capiteles, por grandes conchas, los cornisamentos de las mismas arcadas que van acompañados de amplias volutas (una comparación con el portal de la Capilla Caracciolo di Vico en San Giovanni a Carbonara en Nápoles puede calibrar eficazmente, a distancia de poquísimos años la diferencia entre los arcos burgaleses y el rigor arqueologizante de la obra napolitana); los gigantescos jarrones colocados al final de la rampa central; las columnas abalaustradas rematadas por capiteles zoomorfos y repletas de criaturas fantásticas que en su estructura compositiva reflejan la concepción expresada en las Medidas según la cual la balaustra no se define como elemento autónomo, es decir como candelabro según la óptica de los seguidores del Vitruvio, pero como parte que completa la columna en sí. De hecho Sagredo escribe: «el balaustre es como un tronço de coluna retrayda y el assiento redondo como suelo de orinal por lo qual es de muchos así llamado [...] Quando quieren armar alguna coluna monstruosa: supple todo lo que falta para el alto que ha de aver: con buxetas y vasos antiguos/ diversamente formados/ cubiertos y vestidos de follagería y otras labores fantásticas: puestos uno sobre otro: y encíma de todos assientan el balaustre: el quel no es menos atavíado: el vientre de sus hojas antiguas/ y el cuello de sus estrías: de otras labores que a proposito le vengan» (fig. 7$)^{32}$. Otros elemen-

\footnotetext{
${ }^{311}$ Ibid., fol. CVIv.

"S. Scbastián López. Las fuentes inspiradoras de los grutescos del plateresco, en «Príncipe de Viana», nn. 104-105, 1966, p. 230.
} 



17

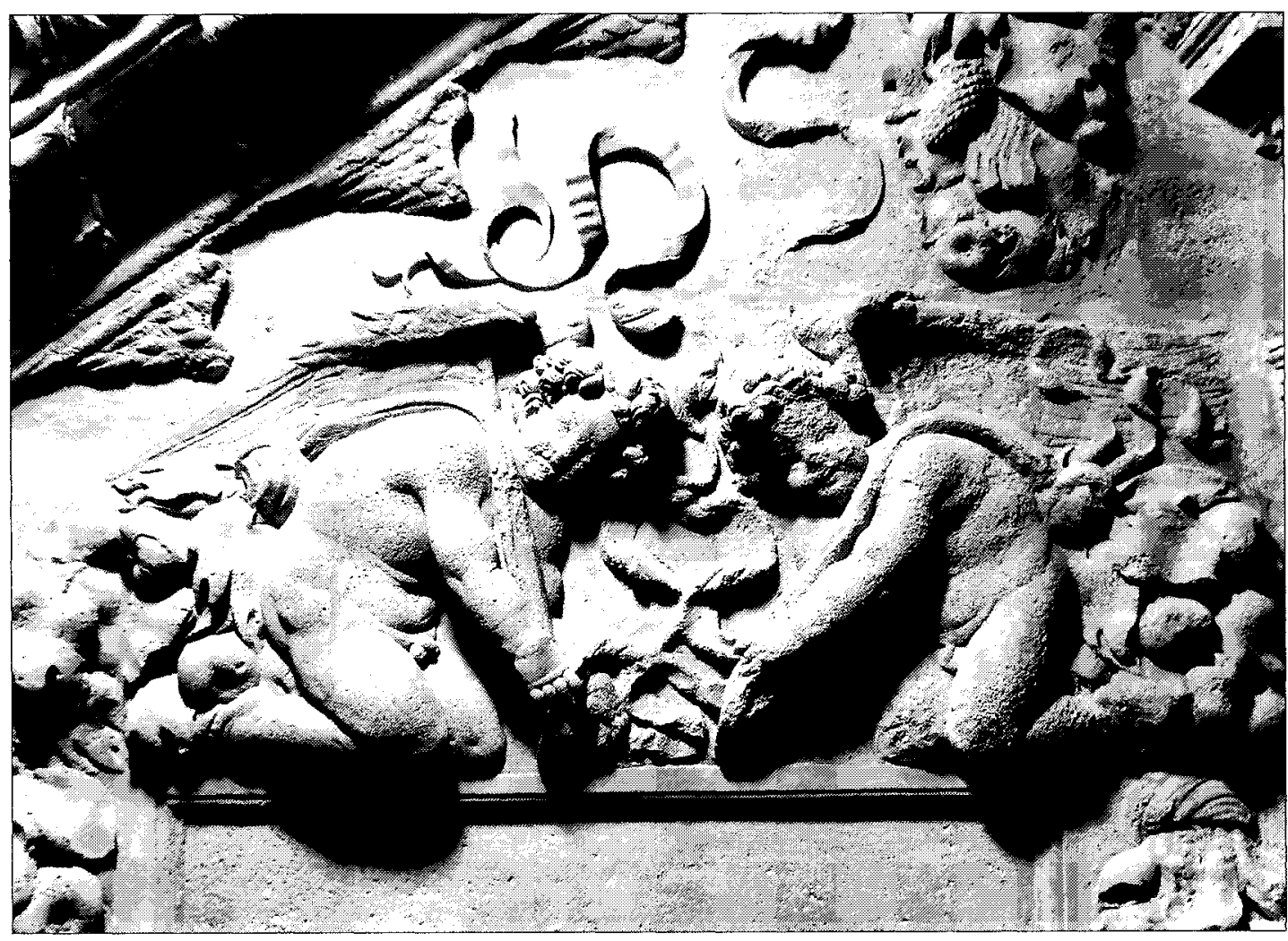

19

Fig. 17. Codex Escurialensis, fol. 20v, El Escorial, Biblioteca del Real Monasterio, ms. 28.II.12. Fig. 18. Escalera Dorada, Detalle del arco izquierdo, Burgos, Catedral.

Fig. 19. Escalera Dorada, Pareja de ángeles, Burgos, Catedral. 
tos son los grifos colocados sobre el lugar del cornisamento y especialmente las grandes columnas abalaustradas, sin una funcionalidad, colocadas horizontalmente apenas un poco elevadas sobre los dos sarcófagos a la antigua (fig. 6), las cuales en su particular disposición parecen seguir aún las palabras de Sagredo cuando afirma que este género de columnas se pone en la obra «mas por atavío que por necessidad», sin respetar las normas clásicas y en armonía con el espíritu «libre» de la decoración plateresca (fig. 8) ${ }^{33}$.

Siguiendo las afirmaciones que realiza uno de los más acreditados estudiosos de Sagredo, Nigel Llewellyn, el gran espacio dedicado entre las páginas de las Medidas a la columna monstruosa o abalaustrada asume un significado particular: tratada como alternativa a los ordenes vitruvianas, pero elevada por Sagredo al mismo nivel de importancia, la columna abalaustrada supondría una característica distintiva del plateresco, volviéndose por tanto un símbolo peculiar de un estilo arquitectónico «nacional ${ }^{34}$. Sagredo, en definitiva, quiere legitimar, dando un fundamento teórico estable, una tipología decorativa que en España estaba ya bien difundida desde inicios del siglo XVI. Una correcta lectura estilística de la Escalera Dorada, por tanto, no puede prescindir de esta más compleja perspectiva de juicio. Es significativo, a propósito, que en el retablo mayor de la Capilla del Condestable de la Catedral de Burgos, la escena central haya sido encuadrada por dos columnas abalaustradas completamente similares a aquella que ilustra el texto sagrediano, y todavía más que Siloe, algunos años más tarde en el 1529, empleará de modo sistemático la columna abalaustrada en el segundo orden del patio interior del Colegio de los Irlandeses (o Colegio Fonseca) de Salamanca, continuado después por Juan de Alava, una obra que en la consecución clásica de las arcadas del primer orden retoma, en palabras de Gómez-Moreno, la disposición «de los teatros y anfiteatros romanos tal como fue interpretada en

${ }_{32}$ D. de Sagredo, op. cit., fol. C. Sobre la base de las fuentes vitruvianas, la tratadística del renacimiento italiana ha reservado una atención completamente secundaria a las columnas o a los elementos decorativos que no entrasen en los ordenes arquitectónicos canónicos, y mucho menos ha consentido a la columna monstruosa definirse como una tipología arquitectónica autónoma en el convencimiento de que el uso de la columna abalaustrada fuese desconocido por los antiguos (Wittkower por el contrario ha demostrado que, aunque solo esporádicamente, esto género de columnas fue usado por Ios romanos. Cfr. R. Wittkower, Il Balaustro rinascimentale e il Palladio, en «Bollettino del Centro Andrea Palladio», X, 1968, pp. 332-46). Entre los teóricos del Renacimiento cualquier interés se vierte con énfasis sobre el candelabro utilizado como decoración por sí mismo. (cfr. L. B. Alberti, L'Architettura [De re aedificatoria], VII, XIII, fol. 130, ed. it. a cargo de P. Portoghesi con trad. de G. Orlandi, Milán 1966, Il, p. 630). Filarete hace referencia, pero solo como casos excepcionales y atípicos, a columnas de formas inspiradas en el mundo de la naturaleza, sobre todo árboles, enriquecidas con decoraciones vegetales y animales (Antonio Averlino, llamado Filarete, Trattato di architettura, codice Magliabechiano II.IV. 140, fol. 57, Florencia, Biblioteca Nacional). Más atento al tema se muestra Francesco di Giorgio: en el fol. 15r del Codice Saluzziano, en la parte superior, a la derecha, diseña dos candelabros acompañados respectivamente de las siguientes denominaciones: cholonna a chandeliere y cholonna a balausti. Uno de los comentarios que hace al respecto es: «Anco le colonne a balagusti e candelieri, le quali con gentilezza di magistero molte ornate fero». No es por tanto un caso en que Maltese, en la edición crítica del testo del Martini haya considerado estos elementos como columnas verdaderas y propias, y por tanto capaces de definirse como ordenes arquitectónicos, sino más propiamente como columnillas a modo de candelero utilizadas solamente para fines decorativos (F. di Giorgio Martini, op. cit., II, p. 57). En este sentido me parece significativo el uso que proponen por ejemplo, Luca Pacioli en la llamada Porta Speciosa (De Divina proportione, 1509) y fra Giocondo y Cesare Cesariano en sus ediciones vitruvianas (M. Vitruvitus per locundum solito castigatior factus, cum figuris ef tabula, ut iam legi et intellegit possit, Venecia 1511, fol. 26r. Di Lucio Vitruvio Pollione De Architectura libri dece traducti de latino in vilgare, affigurati, commentati e con mirando ordine insigniti, Como 1521, III, III, fol. LX).

3. Eficazmente Marías y Bustamante han evidenciado en su estilo plateresco el común denominador sea de la corriente gótico-pronto renacimental, sea de aquella renacentista introducida en tierras ibéricas por Siloe y por Machuca, dejando de lado su violenta y absoluta oposición en el plano estrechamente arquitectónico. Sólo más tarde, con Juan Bautista de Toledo y Juan de Herrera, la abundancia decorativa del plateresco cederá paso a una decoración, siempre clásica pero más sobria, que los historiadores españoles definen significativamente con la etiqueta de estilo desornamentado (D. de Sagredo, op. cit., pp. 75-76).

34 Llewellyn ha dado incluso una compleja explicación etimológica para sostener sus hipótesis. El término latino balaustimum, que en español se traduce con la palabra granada, vendría a asumir un significado explícito en relación a los bien conocidos sucesos políticos que interesaron a la monarquía castellana a finales del siglo xv. Cfr. N. Llewellyn, Two notes on Diego da Sagredo: 1. The comice and Face. 11. The balauster and Pomegranate, en «ournal of the Warburg and Courtauld Institutes». 40, 1977. pp. 292-300. 

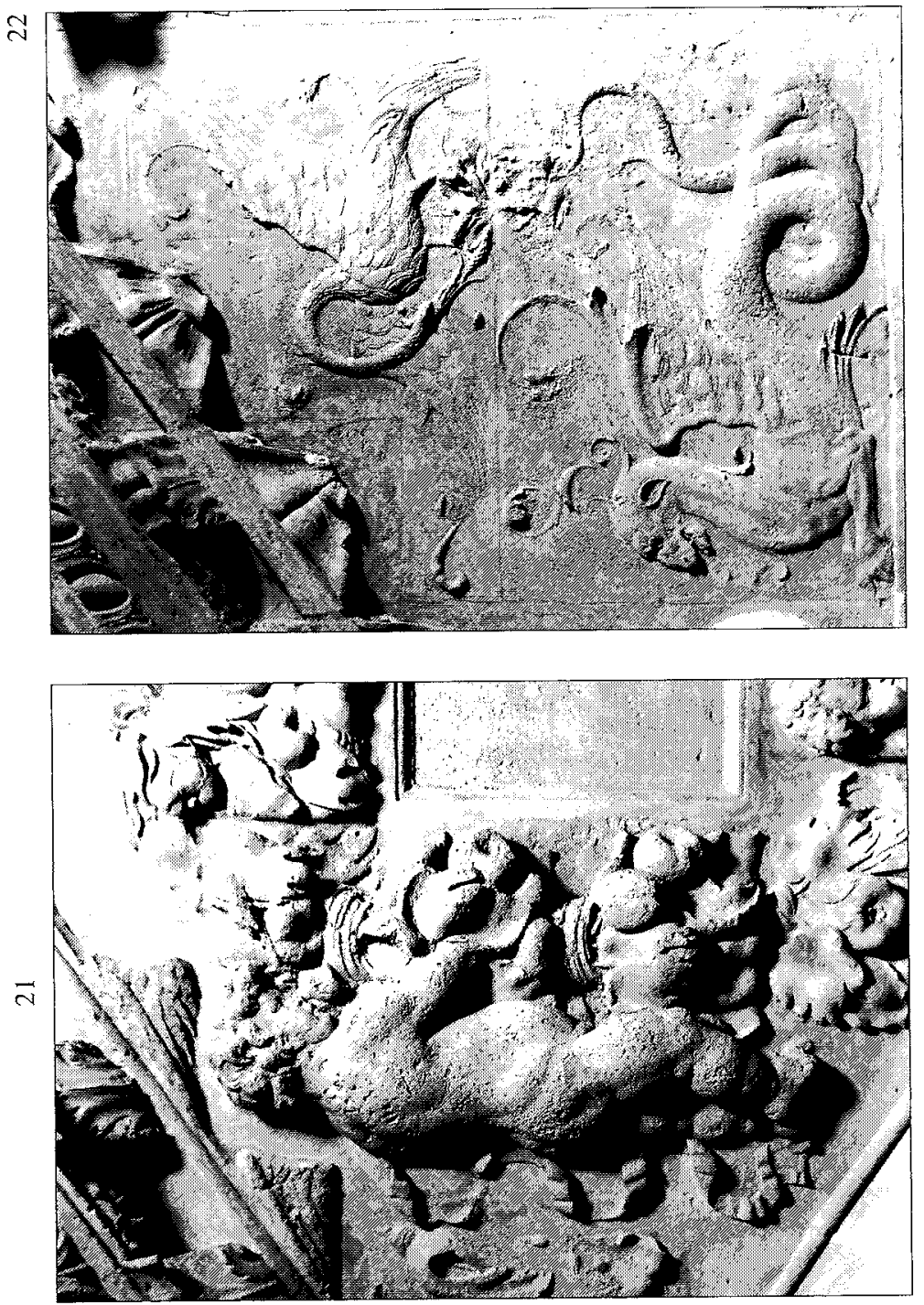

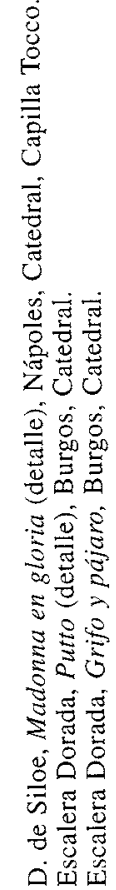

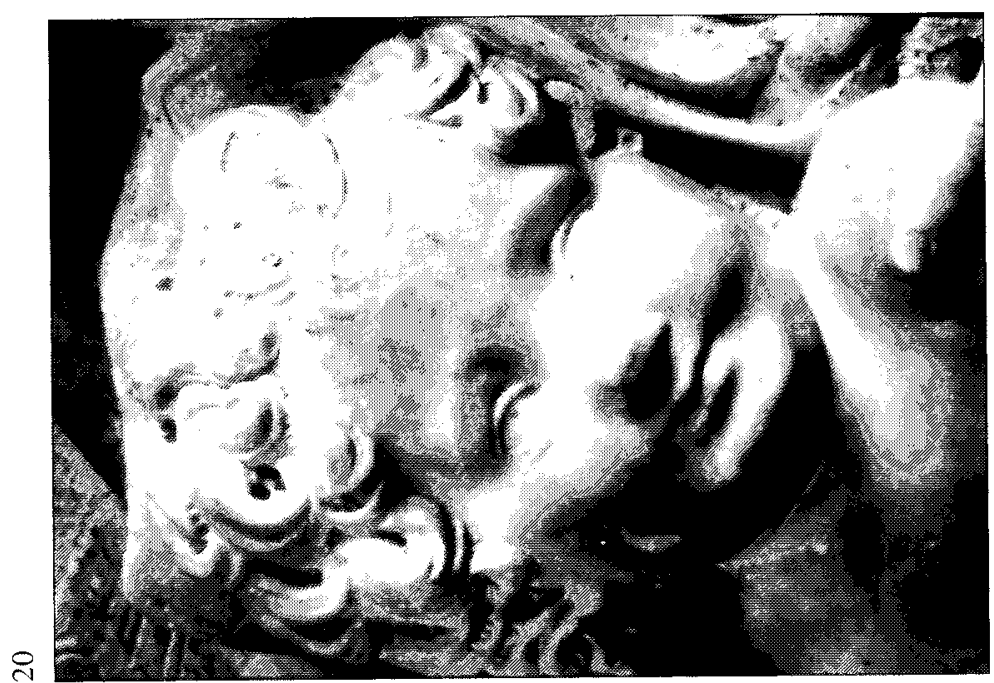

จุล่

的部定 
el Palacio Venecia en Roma y tardíamente por los Sangallo» ${ }^{35}$. La comparación con otra de las «águilas» españolas puede eficazmente delinearnos los diversos recorridos comenzados en su retorna a la patria por los artistas que han tenido en común el mismo equipaje formativo de experiencias artísticas. Pedro Machuca de hecho adopta en el Palacio de Carlos V en Granada un lenguaje inspirado en el más puro clasicismo (basta pensar en la nítida sucesión de dórico y jónico, de los dos órdenes de columnas del patio circular) anticipando, en el rechazo de la estética plateresca, los éxitos más sobrios y equilibrados de la arquitectura de mitad de siglo. Siloe, por el contrario, aunque en las obras de la Catedral de Granada no renuncia jamás a aquella exuberancia decorativa, propia del plateresco, che no por casualidad le valió el reconocimiento de fray José de Sigüenza, «era amigo de cargar de follajes» y las lacónicas palabras de Francisco de Holanda que lo recuerdan como, «Siloe, de follages en Granada» ${ }^{36}$.

Pero ahora ya es tiempo de entrar de lleno en el análisis de las decoraciones esculpidas en la Escalera Dorada.

En su famoso libro sobre las «Aguilas del renacimiento español», Gómez-Moreno entendía en el empleo de la columna abalaustrada del arco central una fuerte componente lombarda, bien familiar a un artista como Siloe que en Nápoles no había ciertamente dejado de echar más de una ojeada a los mármoles dejados por la tupida colonia de escultores lombardos, que trabajaron sobre todo en el periodo aragonés ${ }^{37}$. La indicación de Gómez-Moreno es significativa en cuanto, en el más amplio cuadro del génesis del estilo plateresco, la influencia de la arquitectura lombarda de fines del siglo xv es bien evidente, si bien todavía no se ha definido completamente ${ }^{38}$. Aunque Harold Wethey advertía un eco septentrional ente las esculturas siloescas, que se señalaba en la inserción de medallones con cabezas de perfil incluidos en la balaustrada mientras en el otro lado las parejas de ángeles le sugerían más apropiados acercamientos a la vereda de la tradición de la escultura florentina y romana del Quatrocento. Según el investigador americano el apogeo de la decoración se alcanzó tanto bajo el aspecto cuantitativo, como desde el punto de vista de la invención, de las dos figuras de jóvenes desnudos que cabalgan animales monstruosos esculpidas con gran resalte en las extremidades de la Escalera y realizadas siguiendo los desnudos Miguelangelescos de la bóveda de la Capilla Sixtina ${ }^{39}$. Más adelante, Wethey incidía en aquella que es, en efecto la característica predominante de la decoración de la Escalera, baste decir, para utilizar sus palabras, el «vasto conocimiento de la Roma antigua [y] de la Roma renacentista» ${ }^{40}$. De las intervenciones de Santiago Sebastián de los años sesenta hasta hoy en día, más allá de la amplia referencia a modelos de la Italia septentrional por cuanto concierne a la génesis de la decoración del renacimiento español (constante punto de referencia son las esculturas de la Cartuja de Pavia y la Capilla Colleoni en Bergamo $)^{41}$, la crítica española ha individualizado en las estampas de algunos grabadores como Nicoletto da Modena, Govanni Antonio da Brescia, Agostino de' Musi llamado Agostino

\footnotetext{
${ }^{35}$ M. Gómez-Moreno, op. cit., p. 61. La columna abalaustrada aparece en otras obras de Diego de Siloe: en el orden superior del sepulcro de Rodrigo de Mercado en Oñate, como división de los sitiales del coro monasterio de San Jerónimo en Granada y en la portada de la sacristía de la vecina catedral. Sobre esta última se debe señalar un ensayo, que afronta en clave iconográfica el uso de la columna abalaustrada: J. M. Montijano García, Representación y símbolo en la arquitectura: una lectura alternativa de la portada de la sacristía de la Catedral de Granada, en «Boletín de Arte», 13-14, 199293, pp. $91-103$.

${ }^{30}$ Cfr. J. B. Bury, The stylistic term «Plateresque», en «Journal of the Warburg and Courtauld Institutes», 39, 1976, p. 222. Para Francisco de Holanda véase F. J. Sánchez Cantón, op. cit. I, p. 120

37 M. Gómez-Moreno, op. cit., p. 45.

38 J. B. Bury, op. cit., p. 217.

${ }^{39}$ H. E. Wethey, The Early Works cit., p. 329.

40 H. E. Wethey, Escaleras cit., p. 301.

${ }^{4}$ Cfr. por ejemplo el resumen de A. C. Ibáñez Pérez, Notas para el estudio de la decoración burgalesa del siglo xvi, en «Masburgo», I, 1978, pp. 93-111, según el cual la disposición de los elementos decorativos y la preferencia mostrada al dato de la naturaleza son los más evidentes puntos de contacto con el espíritu de la decoración española.
} 


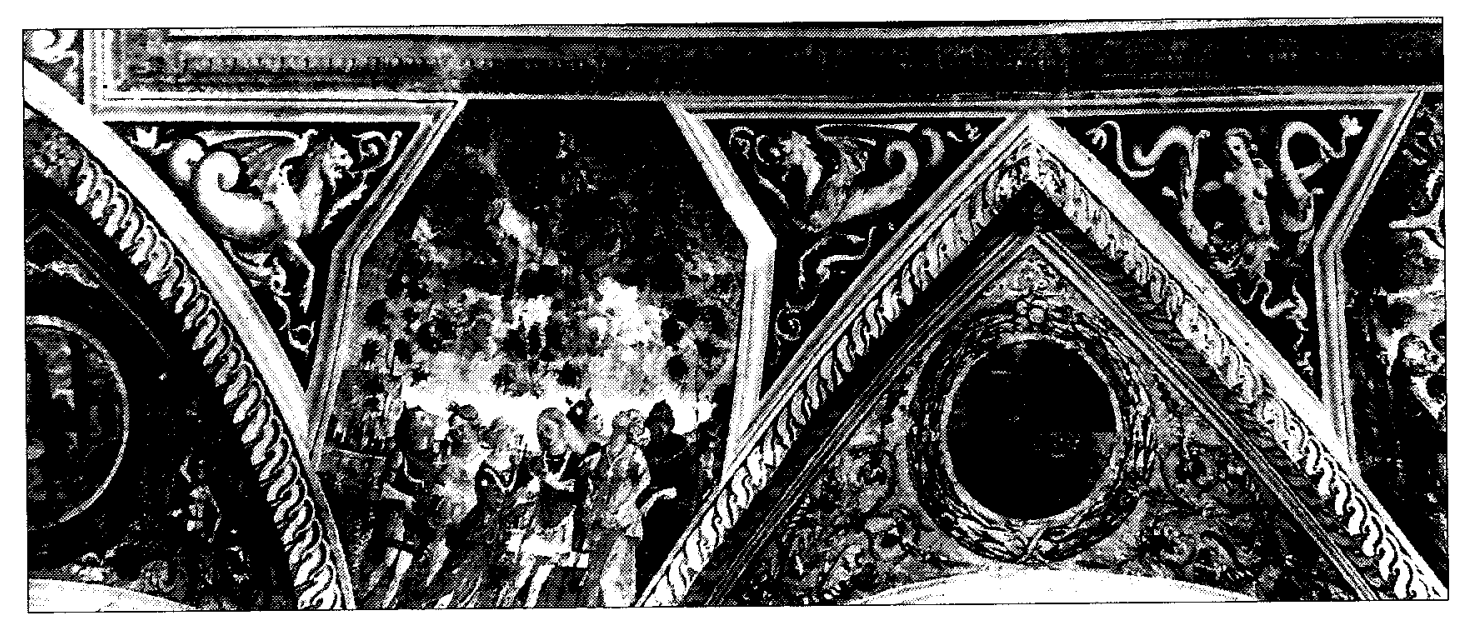

23

24

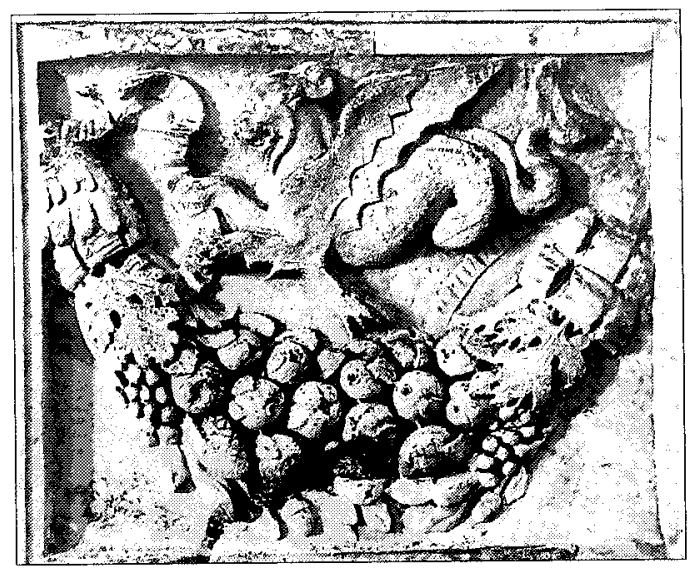

25

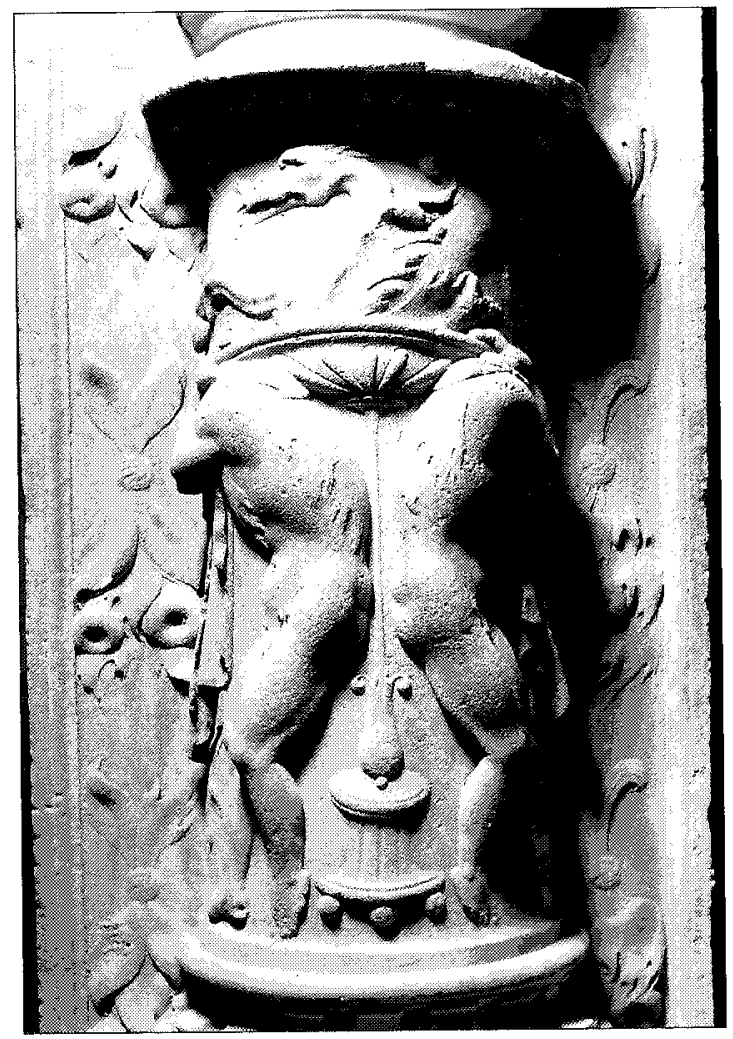

Fig. 23. Pinturicchio y taller, Bóveda de la Sala de las Sibilas (detalle), Vaticano, Apartamento Borgia

Fig. 24. Sarcófago romano (detalle de un grifo), Roma, Galería Borghese.

Fig. 25. Escalera Dorada, Pareja de hombres desnudos, Burgos, Catedral. 
Veneziano la fuente principal de los modelos decorativos de la Escalera Dorada. En particular Sebastián indicaba la derivación, de los delfines que recorren en el primer orden de la balaustrada, de algunas estampas del miniaturista milanés fray Antonio da Monza, mientras que de los grabados de Agostino Veneziano vendrían tanto los grifos puestos en la rampa central de la Escalera, como otras figuras zoomorfas como la larga gola de la serpiente. Por la parte más «a la romana», es decir el intradós del arco mediano (fig. 28), los modelos serían dados por parte de algunas estampas de Giovanni Antonio da Brescia. Nicoletto da Modena, finalmente, también podía haber inspirado la tipología del animal monstruoso montado por el joven desnudo de la parte más a la derecha ${ }^{42}$.

En los últimos años Margarita Fernández Gómez ha realizado un detallado análisis de los relieves de la Escalera Dorada sobre la base de un amplio bagaje iconográfico constituido por los diseños de los elementos individuales de la decoración plástica, aunque por otra parte por lo que concierne a los modelos figurativos la investigadora se limitaba a recorrer las posiciones ya indicadas por Sebastián ${ }^{43}$. Puesto en evidencia que en la escalera burgalesa el tradicional repertorio decorativo vegetal adoptado todavía en la coetánea tumba Acuña, ha desaparecido casi completamente para dar paso a una decoración prevalentemente zoomorfa y con connotaciones fantásticas, M. Fernández Gómez ha tratado de definir el carácter de la decoración siloesca haciendo un recorrido que desde la Escalera Dorada llega hasta los bajorrelieves de la portada de la sacristía de la Catedral de Granada. El conjunto decorativo de la escalera burgalés, sobre la base de un lenguaje común inspirado al «mas puro humanismo clásico», presentaría dos características distintas: por un lado la inmediata evidencia del aspecto que podríamos llamar «humano»: ángeles y putti de grandes dimensiones y de relieve pronunciado; y por otra parte y por el contrario, bajorrelieves casi planos, esculpidos si orden aparente en las paredes secundarios, como si el artista hubiese querido colocar aquí un mundo palpitante de criaturas fantásticas que se van descubriendo cada vez que se observan. La fuente primaria de este acentuado interés por los aspectos más irreales y fantasiosos de la decoración a grutescos y de su unión con los elementos del mundo real sería todavía una vez más Nicoletto da Modena, con sus casi ochenta grabados en los cuales figuras humanas perfectamente dibujadas cohabitan con animales de semblanza monstruosa e inquietante. En lo específico la investigadora indicaba dos estampas fechadas en 1507, la primera lleva la inscripción «VN BEL MORIR TVTA/ LA VITA HONORA», la segunda tiene como objeto principal El juicio de Paris y Orfeo que amansa las fieras, en los cuales se muestran de nuevo sobre todo figuras de terribles pájaros de largos picos y dragones de lengua (figs. 12-13) ${ }^{44}$.

La prevalencia de los motivos zoomorfos se acentúa todavía más en los relieves de las pilastras que sostienen la cubierta del crucero de la catedral burgalesa, adscritos por M. Fernández Gómez a Diego de Siloe ${ }^{45}$. La acusada simetría de las figuras esculpidas dentro de re-

\footnotetext{
42 S. Sebastián López, La Escalera cit., p. 354.

${ }_{4.3}$ M. Fernández Gómez, El lenguaje de los grutescos y Diego de Siloe, en «Academia», 59, 1984, pp. 263-311 e Idem, Los grutescos en la arquitectura española del protorrenacimiento, Valencia 1987, pp. 283-300.

44 Cfr. The lllustrated Bartsch, XXV, pp. 126, 233.

45 Para dar esta atribución a Diego de Siloe, M. Fernández Gómez se apoya exclusivamente en la repetición de motivos ya encontrados entre los paneles de la Escalera. La historia externa de estas esculturas ocupa un espacio temporal tan amplio y carecemos de documentación que nos permita situar con precisión la ejecución de los relieves que se estan examinando. Los trabajos, comenzados en 1466, prosiguieron en 1502 bajo la dirección de Simón de Colonia. En 1535 se manifestaron en los elementos sustentantes los primeros síntomas del desastre que, cuatro años después, llevará a la ruinosa caída de la cubierta central. M. Fermández Gómez sostiene que la obra de reconstrucción, iniciada inmediatamente por Francisco de Colonia y por Juan de Vallejo para concluirse en 1568, difícilmente podía incluir a las esculturas situadas en la base de las pilastras, que sobrevivirían con toda probabilidad a la caída de las estructuras superiores, gracias a su colocación más protegida. En consecuencia la realización de estos relieves se situaría en los años precedentes al 1539 . Para una análisis de la descripción de estos paneles véanse los ensayos recordados anteriormente de M. Fernández Gómez, en par ticular Los grutescos cit., pp. $291-98$
} 

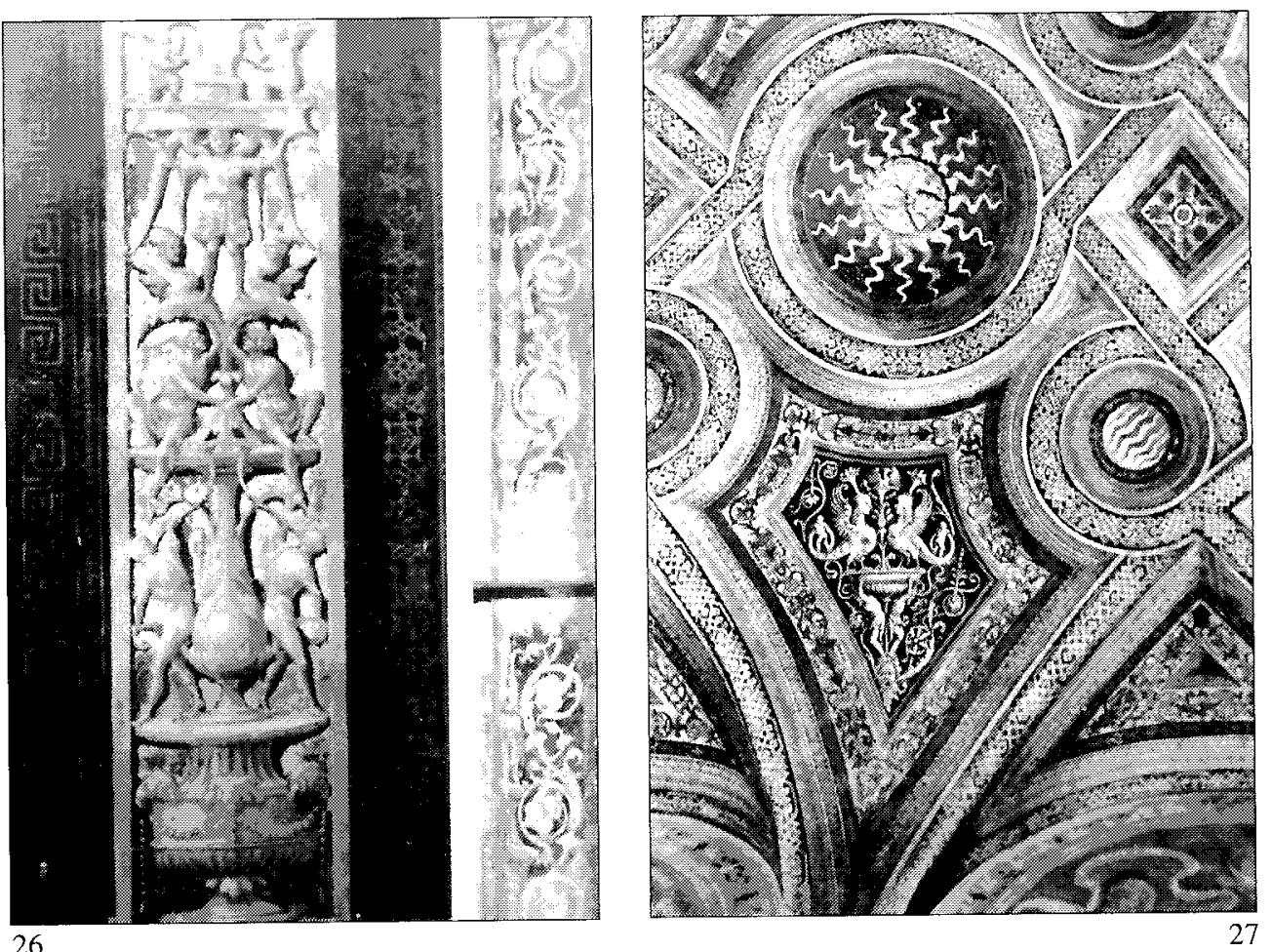

26

28

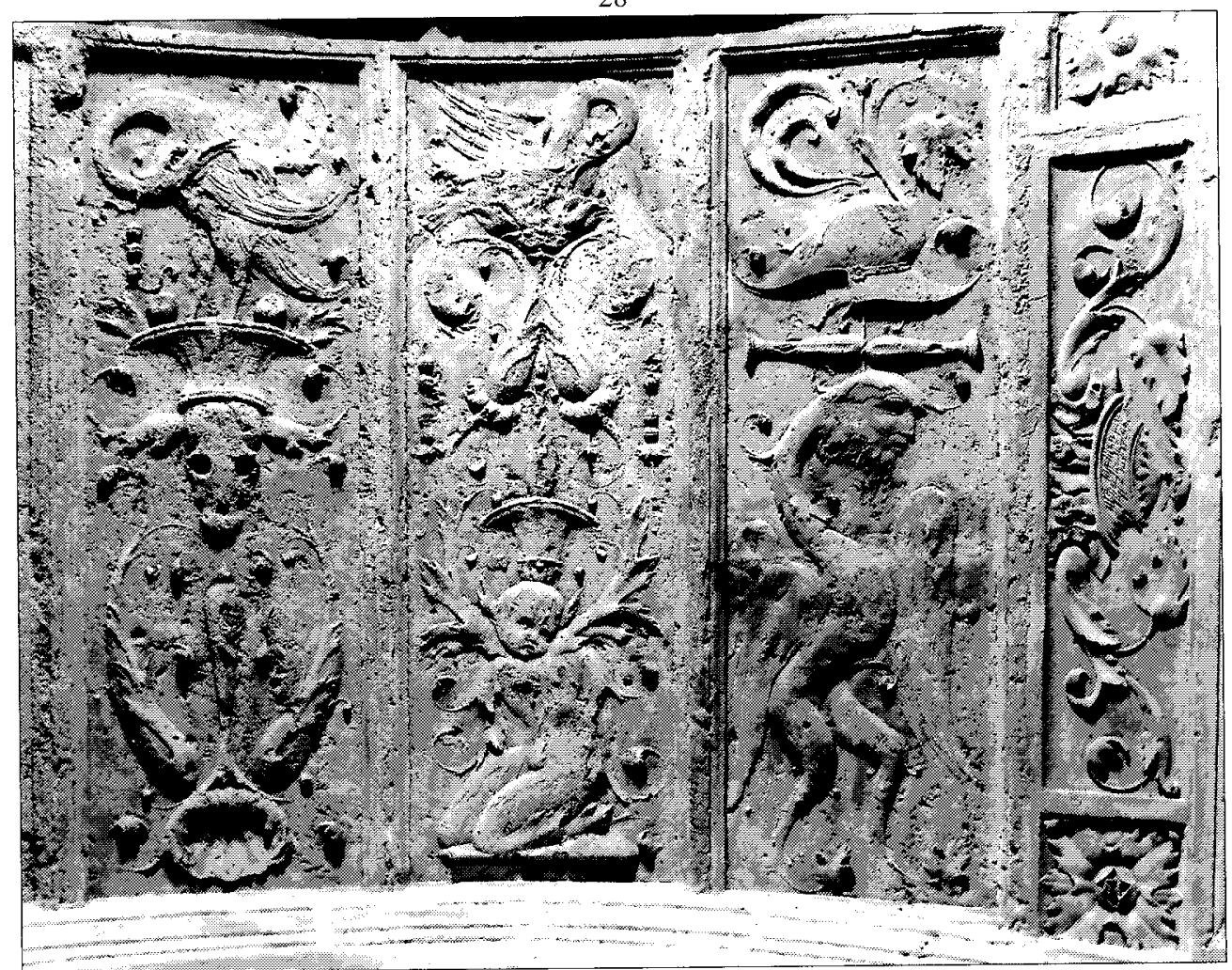

Fig 26. L Signorelli, Decoración de la Capilla de San Brizio (detalle), Orvieto, Catedral.

Fig. 27. Pinturicchio y taller, Bóveda de la Sala del Credo (detalle), Vaticano, Apartamento Borgia.

Fig. 28. Escalera Dorada, Intradós del arco mediano (detalle), Burgos, Catedral. 
cuadros rectangulares, la hipotética búsqueda de una mayor equilibrio compositivo que estaría todavía ausente en parte en la Escalera, indujeron a la investigadora a situar los relieves del crucero como obra de una mayor madurez y por tanto unos años posterior, con toda probabilidad realizada en relación con los trabajos documentados de Siloe en la vecina capilla del Condestable, entre 1523 y $1526{ }^{46}$. El enriquecimiento del repertorio ornamental del crucero de la catedral con nuevos motivos (por ejemplo los curiosos animales de cabeza de perro coronada de racimos vegetales) llevarían a una más clara prevalencia del elemento fantástico, característica esta que la investigadora española, junto con la búsqueda de una composición mejor orquestada, señala como línea evolutiva de la poética decorativa de Siloe. Desde este punto de vista, la presencia de putti y ángeles no define más un momento por si mismo de la decoración, sino que se incluye de manera inseparable en el conjunto de los relieves acentuando la relación dialéctica entre el mundo real, humano y el mundo fantástico ya señalado en la escalera burgalés. La acentuación del factor fantástico e imaginario encontraría después una posterior evolución en la decoración de la portada de la sacristía de la Catedral de Granada donde el elemento real (ángeles, figuras humanas) viene completamente suprimido para dar espacio a una secuencia de elementos zoomorfo que se repetirán más veces según precisos esquemas.

$\mathrm{El}$ análisis realizado por $\mathrm{M}$. Fernández Gómez, si por una parte toma una característica innegable de la decoración de la Escalera Dorada en la preferencia dada al elemento fantástico y zoomorfo, denuncia por otro lado al menos un par de puntos débiles. Ante todo me parece azaroso, en un sector insidioso como es el de la decoración del renacimiento, fundamentar atribuciones solamente sobre la repetición de temas decorativos comunes (por otra parte muy difundidos) y, todavía, considerar necesariamente como síntoma de una madurez estilística la búsqueda de un mayor equilibrio compositivo, si se tiene bien presente que, por lo que respecta a los relieves del crucero, el escultor se ve a trabajar dentro de los rígidos límites de los pequeños recuadros rectangulares que no ofrecen ciertamente aquella libertad de diseño que por el contrario, representa propiamente el elemento más destacable y fascinante, al mismo tiempo de los grutescos de la Escalera Dorada. Pero es la atribución a Siloe en persona la que no se sostiene, al comenzar desde la comparación de las técnicas de ejecución con que han sido realizados los bajorrelieves de las dos obras a examen. La fineza de los juegos de claroscuro, la inagotable fantasía en el acercamiento de los distintos motivos que parecen casi perseguirse los unos a los otros, la vitalidad y el sutil estremecimiento que anima las inquietas criaturas de la escalera burgalesa no encuentran una adecuada respuesta cualitativa en las esculturas del crucero, ciertamente de correcta realización, pero casi comprimidas dentro de los marcos, esculpidas en pocos planos con una técnica a veces simplificada, con una diligencia analítica del detalle y, por cuanto concierne a las figuras de las virtudes, con más de un problema al situarlas en perspectiva (fig. 14). Son propiamente estos elementos los que muestran la extrañeza de la mano de Siloe en esta obra, mientras que comparaciones más puntuales me parece que deban divisarse en los medallones que se sitúan a lo largo de los lados de la vecina tumba de don Gonzalo de Lerma, mandada hacer a Felipe Bigarny en el 1524 (fig. 16) ${ }^{47}$. La relación estilística entre los bajorrelieves de las dos obras, incluso debiendo admitir una superioridad cualitativa de los relieves de santos y virtudes del sepulcro de Lerma y las inevitables diferencias debidas al empleo de distintos materiales (piedra para los relieves del crucero, alabastro para

\footnotetext{
${ }_{46}$ La investigadora señalaba la estrecha semejanza entre las posturas de las parejas de ángeles y de otras figuras humanas presentes in dos paneles de la cubierta central con aquella angélica que sostiene el escudo de los Velasco-Mendoza en la reja de la Capilla del Condestable, obra maestra de Cristóbal de Andino, firmada y datada en 1523 (id. pp. 296-297). Más adelante señalaba un posible ante quem al apelar a algunos motivos decorativos presentes sobre el portal de la iglesia de la Piedad a Guadalajara, documentado en 1526 (M. Fernández Gómez, Los grutescos cit., p. 298).

47 El contrato de adjudicación de obra, fechado en 8 de agosto, fue publicado por M. Martínez y Sanz, op. cit., pp. 267-69.
} 
la tumba), se manifiesta en la común actitud para alargar los planos en la búsqueda de mayor volumen, con el consiguiente alargamiento de las figuras que da lugar después, especialmente en los tipos femeninos a esas caras amplias y redondeadas de melenas airosas y con una expresión dulce pero como embelesada, ideal de belleza bigarniana. Así también en el marcado detalle lineal que, renunciando al «sottosquadro», modela con la misma sutileza los rostros y los vestidos de los personajes.

Los historiadores del arte españoles han insistido mucho en el papel de los grabados como vehículo de difusión privilegiado de los modelos del renacimiento en la península ibérica ${ }^{48}$. Si por una parte esta forma interpretativa se ajusta para aquellos artistas, como Felipe Bigarny y Francisco de Colonia, que realmente no pisaron nunca tierras italianas, por el contrario resultaría excesivamamente reductivo encuadrar en esta única perspectiva una figura como la de Diego de Siloe, que en Italia había madurado su propia formación directamente sobre los prototipos de aquellos modelos. El repertorio decorativo de la Escalera en realidad, además de las estampas de grabadores como Nicoletto da Modena (cuya actividad se desarrolla como es sabido en la Roma del primer decenio del siglo xvI), encuentra numerosas correspondencias sobre todo con las representaciones que se muestran en los cuadernos y en los códices de dibujos la época, haciendo menos decisiva la hipótesis de una derivación de los modelos realizada necesariamente a través de las estampas. Esto naturalmente no quiere decir que Siloe no trajese consigo a su regreso de Italia algunas estampas para añadir a sus dibujos personales en su «corpus» de apuntes de viaje ${ }^{49}$.

A modo de ejemplo, tomando en consideración en primer lugar los elementos propiamente arquitectónicos, se puede apreciar como los capiteles corintios de los arcos laterales encuentran estrechas semejanzas con algunos capiteles dibujados en estudios de diversos cornisamentos en los fols. 12 y 15 del Codice Barberiniano Latino 4424 de Giuliano da Sangallo y con el capitel que aparece en el frontispicio de la edición toledana de las Medidas del Romano. Se trata de una derivación «reducida» de los capiteles corintios del Pantheon (aquel que aparece en el fol. 15 del Barberiniano lleva inscrito «S.M. RITONDA AL PORTICO» es decir el pronaos del Pantheon) con una doble fila de hojas de acanto, caulículos muy pronunciados y una flor al centro del ábaco ${ }^{50}$. Por el contrario los capiteles zoomorfos que rematan las columnas

\footnotetext{
${ }^{48}$ Santiago Sebastián, que junto con Camón Aznar ha sido uno de los asiduos estudiosos de la arquitectura y de la decoración plateresca, ha aportado numerosos ejemplos en la península ibérica de derivaciones, más o menos literales de estampas italianas del renacimiento. El escultor Nicolás de Vergara utilizó como modelo para la decoración del parapeto del púlpito de la iglesia de San Esteban en Burgos (hacia 1520) un grabado de Zoan Andrea del 1505; en la riquísima decoración de gusto clásico de la fachada de la Universidad de Salamanca, donde según Camón Aznar «los recuerdos clásicos [...] aparecen trabajados con sensibilidad idónea al tema, fragante de pathos antiguo» (La arquitectura plateresca, Madrid 1945), el panel inferior derecho del portal deriva de una estampa de Nicoletto da Modena que lleva la inscripción VICTORIA AVGVSTA (The Illustrated Bartsch, XXV, p. 129). Cfr. S. Sebastián López, Las fuentes cit., pp. 229-232.

${ }^{49}$ En su testamento redactado en Granada el 31 de Enero de 1563 Siloe deja a su discípulo Juan de Maeda todas las «trazas y dibujos, asi de arquitectura como figuras, y una notomía de un brazo y una pierna de un cuerpo...» (E. Llaguno y Amírola, Noticias de los arquitectos y arquitectura de España desde su restauración, Madrid 1829, I, p. 310). Por desgracia el corpus grafico siloesco cuenta con poquísimos y controvertidos números, no consintiendo bajo tal aspecto trazar una finonomía definida del artista. Loa únicos dibujos atribuibles a Diego son relativos a un arco trunfal para una escenografía (L'època dels genis, catálogo de la exposición, Barcelona 1987, p. 59, n. 65), una mensula para la puerta lateral de la iglesia del Salvador en Úbeda (D. Angulo, A. Pérez Sánchez, Spanish drawings 1400-1600, Londres 1957, p. 58, n. 234) y el proyecto para la Casa de los Miradores de Granada. Cfr. M. Gómez-Moreno. Diego Siloe. Homenaje en el IV centenario de su muerte, Granada 1988, p. 49 (reedición facsímil de la ed. del 1963 con intr. crítica de J.M. Gómez-Moreno Calera). Sobre la controvertida cuestión de un dibujo relativo a una catedral cfr. A. Pérez Sánchez, Historia del dibujo en España. De la Edad Media a Goya, Madrid 1986, pp. 120-21. Otro dibujo, relativo al palacio de la Alhambra de Granada se conserva en el Archivo Histórico Nacional di Madrid, y ha sido atribuido a Diego de Siloe por F. Marías, El largo siglo Xvl, Madrid 1989, p. 373.

50 Para el Codice Barberiniano Latino 4424 de la Biblioteca Apostólica Vaticana cfr. el estudio esencial de C. Hülsen, Il libro di Giuliano da Sangallo. Codice Barberiniano Latino 4424, Lipsia 1910 (reeditado en color en 1984 a cargo de la misma Biblioteca Vaticana).
} 
abalaustradas de la Escalera son bastante semejantes a aquellos que se muestran en la parte baja del fol. 20v del Codex Escurialensis, acompañados de la inscripción «ad hostium et curtile» (figs. 15, 17) ${ }^{51}$. La trabazón de las arcadas laterales recuerda en la sucesión de dentículos, bocelos alternándose con hojas onduladas, ondas y conchas aquella, más elaborada, que aparece en el fol. 11v del Barberiniano, en la parte más a la derecha y que lleva una inscripción relativa a la iglesia romana de san Bartolomeo in Isola, con la diferencia de que la secuencia de conchas que delimita superiormente la trabazón en la de Burgos ha reemplazado los motivos vegetales diseñados por Sangallo. En forma similar al fol. 83 del Codice Coner el estudio de marcos reproducido en la parte baja a la izquierda evidencia una más rica repartición y por coronamiento una faja de hojas onduladas ${ }^{52}$.

Continuando con los elementos figurativos, viene seguramente puesta en evidencia la estrecha relación que hay entre los grifos de los penachos de los arcos laterales (fig. 18) y el pájaro monstruoso que aparece en la parte alta a la derecha en un grabado de Nicoletto de Modena, que representa como objeto principal un sátiro que toca la flauta y que porta la inscripción «ATILA FLA DEI» ${ }^{53}$. La inventiva siloesca, sin embargo, ha transformado el pico alargado del monstruo de Nicoletto en gruesas fauces que se resuelven con racimos vegetales. Para continuar con las estampas de Nicoletto, una idea similar a la que propone Diego para los dos desnudos que montan animales monstruosos se puede recuperar en un grabado del 1507 que representa a Marte sentado entre una multitud de variadas figuras en la cual en la parte baja se ven dos sátiros intentado domar criaturas antropomorfas de rostro satírico ${ }^{54}$. Relaciones se pueden hacer incluso con los putti que montan especies de equinos de cola en forma de hojas en el fol. 58 del Codex Escurialensis, retomados del criptopórtico de la Domus Aurea, pero ciertamente los relieves burgaleses acentúan mucho más las connotaciones fantásticas.

La referencia a la obra de Miguel Angel de la bóveda sixtina indicado por Wethey para los dos desnudos se puede concretar en la figura situada a la derecha sobre la Sibilla Persica por lo que respecta al joven de la izquierda, mientras que la otra escultura siloesca en su postura de la pierna replegada y en la cabellera ondeante nos lleva a relacionarla con el desnudo de la derecha sobre la Sibila Eritrea. Quizá el punto de partida inicial, que viene a confirmar la capacidad inventiva de Siloe al igual que su poder de síntesis de reelaboración de modelos más disparatados que aparecen a través de toda la tradición del renacimiento italiano, se puede hacer partir de la decoración del Perugino de la bóveda del salón del Colegio del Cambio en Perugia. El tondo que representa la Luna está acompañado a los lados por dos ángeles que montan animales monstruosos en actitudes que recuerdan a las de las figuras burgalés, con la singular semejanza entre los dos animales de largo cuello cuyo pelo termina en cogollos de hojas de acanto (fig. 11). Para las parejas de ángeles que sostienen las grandes cartelas a los lados del arco mediano (fig. 19) fueron ya en su tiempo por Ferdinando Bologna relacionados con los putti che están alrededor de la Madonna en gloria de la Capilla Tocco de la Catedral de Nápoles para argumentar la atribución del mármol napolitano a la mano de Siloe ${ }^{55}$. En particular las parejas situadas sobre más allá de las cartelas son indudablemente de la mano del maestro burgalés con posteriores llamadas, en la expresión soñadora y sonriente, todavía leonardesca, a los ángeles del portal de la capilla Caracciolo y en particular al Gesù Bambino de

\footnotetext{
5) H. Egger, Codex Escurialensis. Ein Skizzenbuch aus der Werkstatt Domenico Ghirlandaio, Viena 1906.

52 Codice Coner, Londres, Sir John Soane's Museum. Esta colección de dibujos ha sido atribuida al sangallesco Bernardo della Volpaia. Cfr. T. Buddensieg, Bernardo della Volpaia und Giovanni Francesco da Sangallo. Der Autor des Codex coner und seine Stellung im Sangallo-Kreis, en «Römisches Jahrbuch für Kunstgeschichte», XV, 1975, pp. 89-108.

${ }_{53}$ The illustrated Bartsch, XXV, p. 370.

54 Ibid., p. 127

55 F. Bologna, Problemi della scultura del Cinquecento a Napoli, en «Sculture lignee nella Campania», Nápoles 1950, cat. de la exposición p. 161 .
} 
la tabla Tocco (fig. 20), mientras una ejecución más aproximativa demuestran las otras dos parejas, obra por tanto de un ayudante, cuyo gracioso esquema de los dos putti en posición divergente que se cruzan con las piernas puede haber sido tomado de uno de los relieves esculpidos sobre el estilobato derecho del Arco de Castelnuovo en Nápoles. Para los dos gruesos putti a los lados de las cartelas (fig. 21), también pueden caber en la más característica tipología siloesca (cuerpos corpulentos, expresiones veladamente melancólicas, cabellos esculpidos en grandes mechones, incluso sabiendo que el de la derecha se debe atribuir a un colaborador) se pueden utilizar aquellos términos de parangón algunos putti-cariatide siempre de la «Volta Sistina», como los que se encuentran próximos a la Sibila Eritrea, a la Libica y al profeta Exequiel.

Entre las representaciones de mayor interés debe señalarse el animal alado de larga cola en forma de espira, quizá un grifo marino (fig. 22), que recuerda mucho de cerca, aquellos dibujados en los fols. $45 \mathrm{v}$ y 62 del Codex Escurialensis. Otros ejemplos se pueden recuperar en el Taccuino Sienes S.IV.8 de la Biblioteca Municipal de Siena en el fol. 41 recto y verso ${ }^{56}$, en los monstruos marinos realizados en fresco por Pinturicchio y su taller para el palacio romano de Domenico della Rovere y en los dragones alados pintados en la bóveda de la Sala de las Sibilas en el Apartamento Borgia en el Vaticano (fig. 23). Un prototipo de este animal monstruoso se encuentra en un bajo relieve del II siglo proveniente del Teatro Maritimo de Villa Adriana en Tivoli y todavía más en un grifo de un sarcófago romano, hoy en la Galería Borghese (fig. 24) ${ }^{57}$. El pajaro de grandes alas y de alargado cuello que Siloe ha esculpido más arriba se muestra, con ligeras variantes, otras veces entre los paneles de la Escalera, sobre todo en el intradós del arco central. Además de aparecer en la parte alta en el recordado grabado de Nicoletto de Modena «VN BEL MORIR TVTA/LA VITA HONORA», una tipología símil se encuentra en el fol. 13 del Escurialense. La bellísima pareja de desnudos que sostienen sobre la espalda la copa de un cáliz sobre la que se sitúa una especie de dragón (fig. 25), sin duda uno de las piezas «clave» entre las esculturas de Diego, que al verla nos hace recordar enseguida los modelos miguelangelescos para los famosos «prigioni» de la tumba de Julio II, pero posteriores detalles pueden individualizarse en las figuras realizadas en frescos monócromos en las jambas de la ventana de la Estancia de Eliodoro en el Vaticano. El tema de dos figuras desnudas, atlantes, sátiros, o cariátides, dispuestas simétricamente de espaldas a lo largo del asa de un candelabro es muy común en la decoración del renacimiento, pero la idea de un yugo o de un peso para sostener es mas cercana a modelos miguelangelescos. Un posterior, y más antiguo punto de referencia, podría descubrirse en algunos detalles de la decoración de la capilla de San Brizio en Orvieto de Luca Signorelli, un verdadero y genuino repertorio de variaciones «anatómicas» sobre el desnudo, entre las cuales, en este caso, es digna de mención la pareja de desnudos de la pilastra a la derecha del arco de ingreso, bastante próxima a las figuras burgalesas en el estudio de los cuerpos (fig. 26). Nada impide que Siloe pueda haber visto con sus propios ojos la capilla de Orvieto, incluso es bastante probable que la dramática vitalidad y el clima irreal de los grutescos de Signorelli, haya impresionado fuertemente su imaginación, ya de por sí inclinada a tales tipos de representaciones. Diego recordará este motivo incluso algunos años más tarde, en las decoración de la portada de la iglesia de San Gil en Granada (hoy desmontada y conservada en el Museo de Bellas Artes de la ciudad) ${ }^{58}$. Pero sin

\footnotetext{
56 Véase R. Falb, Il Taccuino senese di Giuliano da Sangallo (intr. de L. Zdekauer), Siena 1902.

57 Las dos esculturas se reproducen en AA.VV., Roma, centro ideale della cultura dell'Antico nei secoli xv e xvl, Milán 1989, pp. 152, 191.

${ }^{58}$ Desnudos bastante semejantes a la pareja burgalesa en lo que respecta al modelado de los cuerpos se ven incluso en el basamento del panel que representa el Camino del Calvario en el coro de madera de la Catedral de Barcelona, en el cual dos jóvenes enfrentados vuelcan en un grueso cáliz el contenido de dos ánforas sujetas a la espalda.
} 
duda, la relación más estrecha entre los que se proponen, se debe buscar en la decoración de la bóveda de la Sala del Credo en el Apartamento Borgia. En uno de los grutescos en fresco dentro de los marcos romboidales de Pinturicchio y su taller aparece una pareja de figuras masculina en el acto de sujetar sobre sus espaldas la copa de un grueso cáliz, similar en todo al ejemplar de Burgos (fig. 27). Entre las esculturas en bulto redondo, la espectacular solución de los terroríficos grifos puestos sobre el cornisamento de la arcada central encontrara una réplica apropiada a pocos metros de distancia, en la tumba del canónico Diego de Santander (m. 1523). En resumen los dos sarcófagos a la antigua, colocados a los lados de la rampa semicircular sobre un alto basamento con friso (fig. 6), mostrando un reparto en dos fajas horizontales, separadas por una moldura: la parte superior esta definida por cuatro recuadros decorados con motivos de cornucopias, cestos y racimos vegetales; la faja inferior por su parte presenta una serie de acanaladuras en las basas interrumpidas por cuatro mensulillas con grandes hojas de acanto, esquema que Siloe adoptará después con ligeras variantes en la «doble» tumba de Toribio Gómez y de su mujer en la Iglesia Parroquial de Santiago de la Puebla (Salamanca) ${ }^{59}$. La ejecución, de calidad no muy elevada, deja entender la intervención de un colaborador en los dos sarcófagos de la escalera burgalés.

El análisis de las partes ornamentales de la Escalera Dorada no puede prescindir de una comparación con las decoraciones que en los mismos años Raffaello, Giovanni da Udine y taller estaban realizando en las galerías vaticanas, auténtica clave de parangón del género. Es difícil establecer relaciones más o menos directas, pero una analogía va inclusa en la preferencia dada al elemento zoomorfo, mientras al contrario el repertorio decorativo siloesco parece remontarse a una época anterior ${ }^{60}$.

\footnotetext{
${ }^{59}$ La aparición de fajas o molduras horizontales en las que aparece una gruesa hoja de acanto se encuentra muy a menudo en las obras del maestro burgalés. En particular, el tema de la hoja de acanto recostada sobre un papiro desenrollado, además de los casos recordados, aparece, alternado con cabezas de putti, tanto en el retablo de la misma Capilla de Toribio Gómez, como en los altares de la Purificación y de San Pedro en la capilla del Condestable, mientras que en el basamento del retablito de Santa Ana en la Capilla Acuña es utilizado para separar el bajorrelieve del Cristo muerto de los escudos familiares.

${ }^{60}$ Sobre Galerías es esencial el ensayo de N. Dacos, Le Logge di Raffaello, Roma 1986 (II ed. Actualizada). Para las decoraciones véanse en particular las pp. 31-37
} 